\title{
los acueductos romanos
}

C. FERNANDEZ CASADO, Dr. Ingeniero de Caminos

$535-3$

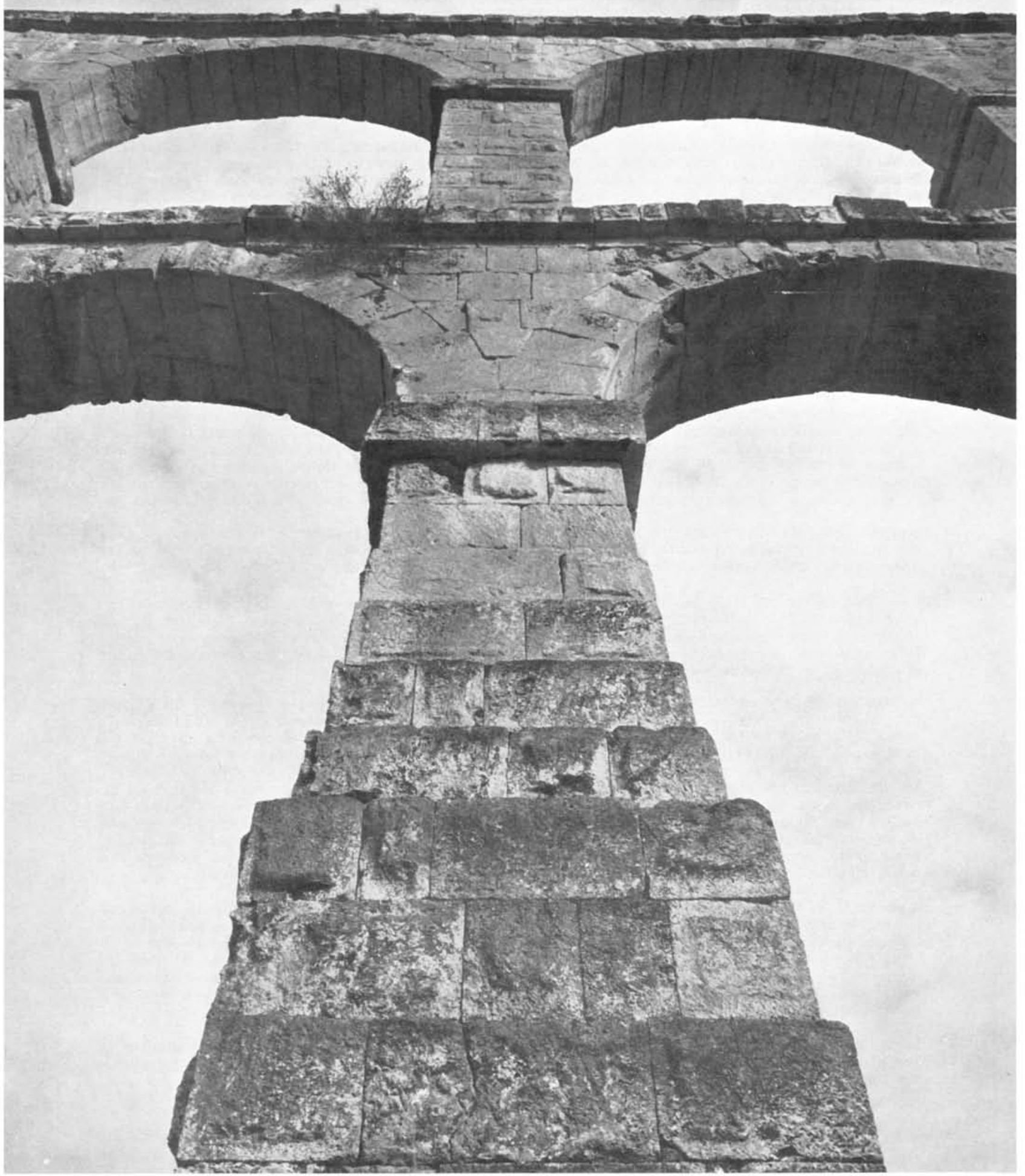




\section{los acueductos de los romanos}

El tema del puente romano se enriquece al considerar las obras de fábrica que en las conducciones de agua (ductionis aquae) soportan el canal sobre el terreno mediante arcadas (arcuatiónibus), obras que denominamos acueductos, tomando el sentido reestricto de la palabra, que también puede aplicarse a toda la conducción en sentido general. Esta especialidad del puente: el acueducto, es típicamente romano, y no sólo porque surge en Roma como solución a problemas planteados por primera vez en su suelo, sino porque representa una de las realizaciones donde el genio romano se manifiesta de un modo más cumplido, siendo, por un lado, eficaz instrumento para el logro de sus objetivos inmediatos más propios, y for otro lado, meta perfecta a la necesidad de todo pueblo de encontrar una expresión propia a través de las artes plásticas.

Anteriormente, en Oriente y Grecia, se había resuelto el problema de la conducción de aguas para abastecimiento de ciudades y para desaguie de lagunas. Los romanos heredaron las técnicas correspondientes de estos pueblos, así como las de sus antecesores los etruscos, y las aplicaron primero para el segundo fin de los indicados, en desagüe de terrenos pantanosos y en el de saneamiento de su propia ciudad. De los artificios que hoy día empleamos en la construcción de abastecimientos, poseían desde el principio el canal a nivel superficial o enterrado en galería, y después el sifón que fue invención de los griegos. E1 acueducto sobre arcadas que se repiten monótonamente a cientos y hasta más de un millar, fue la invención romana.

El problema del acueducto aparece cuando ya están resueltos los del puente y los del arco honorífico o triunfal, y toman de aquél la repetición del motivo y de éste la verticalidad y monumentalidad solemne. A su vez, el acueducto reacciona sobre el puente, imponiéndole la rasante horizontal que el agua exigió a su coronación, rompiendo con la geometría ritual de simetría a dos vertientes y, en consecuencia, con la variabilidad de luces de los arcos, estableciendo la igualdad de todos ellos, lo cual tiene su virtud en el aspecto constructivo.

En una construcción utilitaria y rural, consiguen una realización monumental e imperial que expresa del modo más adecuado el poderío de Roma, manifestando en la propia capital la grandeza de sucesivos pretores y emperadores en competencia, y manifestando en las otras ciudades del imperio el dominio contundente de la metrópoli. En el presente, a distancia de casi veinte siglos, algunos sirven todavía; otros están en perfecta integridad, aunque el agua no circula por su caja, y otros ostentan la dignidad de sus ruinas, mostrando la potencia de esta civilización mediterránea, toda ella orden y claridad.

Símbolo típico de una cultura urbana, enlaza el río, lo más salvaje y potente de la naturaleza, con la ciudad donde el agua, dominada, permite a sus habitantes satisfacer una gama importante de necesidades primarias: la bebida, el baño, el disfrute de las fuentes, da energía a la industria artesana, etc.

La monótona repetición de las arcadas del acueducto con sus pilares en procesión permanente de servidores que aportan la ofrenda del agua, siempre en vela, como el estado romano protector de sus súbditos. En este ritmo unísono de marcha militar, los pilares son centinelas perpetuos que se repiten el santo y seña, servicio del campo a la ciudad y, al mismo tiempo, imposición de la ciudad sobre el campo, y, en definitiva, servicio e imposición del estado a sus ciudadanos.

Se dice que la ruina de los acueductos de Roma motivó el abandono de las viviendas sobre las colinas, y Lyon, una gran urbe en época romana, se empobreció hasta casi desaparecer en la Edad Media, a causa de la ruina de sus acueductos, cuando las invasiones de los bárbaros al comenzar el siglo III. Suerte parecida tuvieron otros acueductos, y sólo los árabes renuevan esta cultura del agua, restaurando algunos acueductos inutilizados por la acción del tiempo y más por el vandalismo de los hombres. También construyen algunas conducciones, aunque de mucha menos envergadura. Hasta los tiempos actuales no se ha llegado a realizaciones con análogo empeño al de los romanos, siendo ejemplar para esto el caso del abastecimiento de Toledo, donde se ha cerrado recientemente un ciclo completo de soluciones al problema, con la traída romana del Guadalerzas, rueda elevadora árabe, artificio de Juanelo renacentista, aguadores con borriquitos modernos, y nuevo abastecimiento del agua con presa de embalse, conducción en canal, acueductos y depósito terminal como en la primitiva romana.

Además de su fidelidad a lo romano, dándonos una muestra auténtica de lo que hicieron y, por consiguiente, lo que fueron estos antepasados, y exigiéndonos, por tanto, un esfuerzo para comprenderlos en esta manifestación de su arte por excelencia, la arquitectura, nos dan también una primera lección de estética, adquiriendo así universalidad y, por consiguiente, actualidad. Desde nuestro punto de vista de ingenieros, esta actualidad es verdaderamente vital y básica para orientarnos en una mejor comprensión de nuestra profesión, y precisamente ahora, cuando las máquinas electrónicas nos dejan sin trabas hacia lo verdaderamente esencial de nuestra labor.

La serie de acueductos españoles constituye una verdadera selección de ejemplares representativos en la evolución del tipo, y van a ser preciosos para intentar este enfoque estético de la arquitectura desde sus raíces más fuertes y sencillas. 


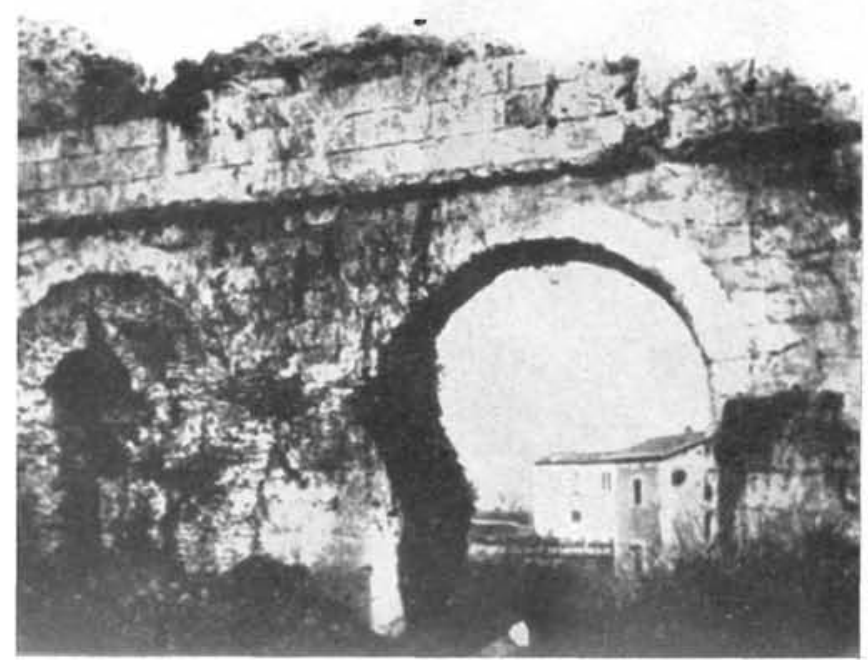

Arcadas del acueducto terminal de la Aqua Marcia, una de ellas con refuerzo posterior. Sobre su caja, restos de la de la Tépula. con refuerzo

\section{acueductos \\ de la ciudad de Roma}

Casi todas las conducciones de agua de la ciudad de Roma, que eran doce en total, llevan el nombre del cónsul o emperador bajo cuyo mandato se construyeron o se reconstruyeron con grandes reformas. En las restantes, es la fuente o el río de donde toman el agua la que califica la conducción.

Por orden cronológico son: Aqua Appia, Anio Vetus, Aqua Marcia, Aqua Tépula, hasta aquí de época republicana; después: la Julia, Aqua Vérgine y Aqua Alsietina, del imperio de Augusto; a continuación: la Claudia, y el Anio Novus, durante Claudio; la Trajana, del emperador español; y la Alejandrina, de Alejandro Severo.

La primera de estas conducciones es la Appia, que se construye en 312-11 a. de J. C., siendo censor Appio Claudio, el mismo que da nombre a la Vía Appia Tenía $16.561 \mathrm{~m}$ (11.130 pasos) con un solo acueducto de $90 \mathrm{~m}$ en la llegada a Roma, cerca de la puerta Capena.

La segunda conducción es la del Anio Vetus, del año 272 a. de J. C., construida con el botín de las guerras contra Pirro. Tenía $63.640 \mathrm{~m}$ y se adaptaba completamente al terreno, siguiendo la curva de nivel para evitar obras elevadas. Existe un acueducto de dos pisos en la zona media de la conducción, pero se construyó por Adriano, sustituyendo un largo contorneo.

La tercera conducción es la Marcia, que debe su nombre al pretor $\mathrm{Q}$. Marcius, bajo cuyo mandato se llevó a cabo en el año 144 a. de J.C. Totaliza $91.400 \mathrm{~m}$ y tiene un acueducto de $9.578 \mathrm{~m}$ sobre arcadas de luz 3,50 y 15 dovelas, con pilares de $3 \times 2,50$, todo de opus quadrata, con ligero almohadillado. Experimenta una reconstrucción radical bajo Augusto, en el año $4 \mathrm{a}$. de J. C., y otras dos bajo Tito y Caracalla. Las arcadas se destruyeron en su mayor parte por Sixto V.

La cuarta se denominó Aqua Tépula, construida en 125 a. de J. C. con un recorrido subterráneo de $17.745 \mathrm{~m}$. Esta es la última conducción de época republicana, pues la siguiente, que es la Julia, se llevó a cabo por Agripa, en el 33 a. de J. C., que, aunque al principio fue prolongación de la anterior para recoger nueva fuente (la fons Giulia), cuya agua

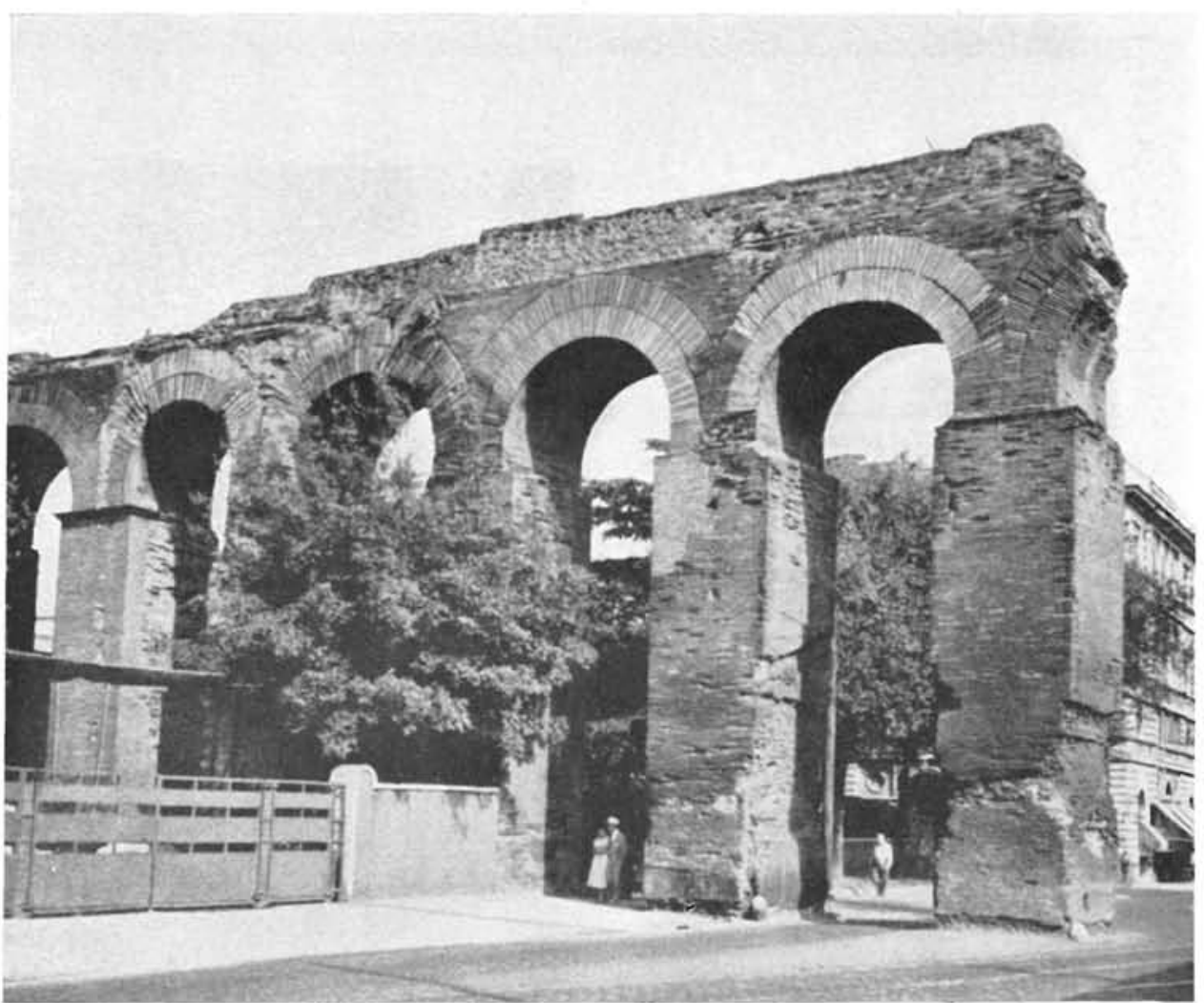

Arcos neronianos en prolongación del Aqua Claudia. Según (102). 


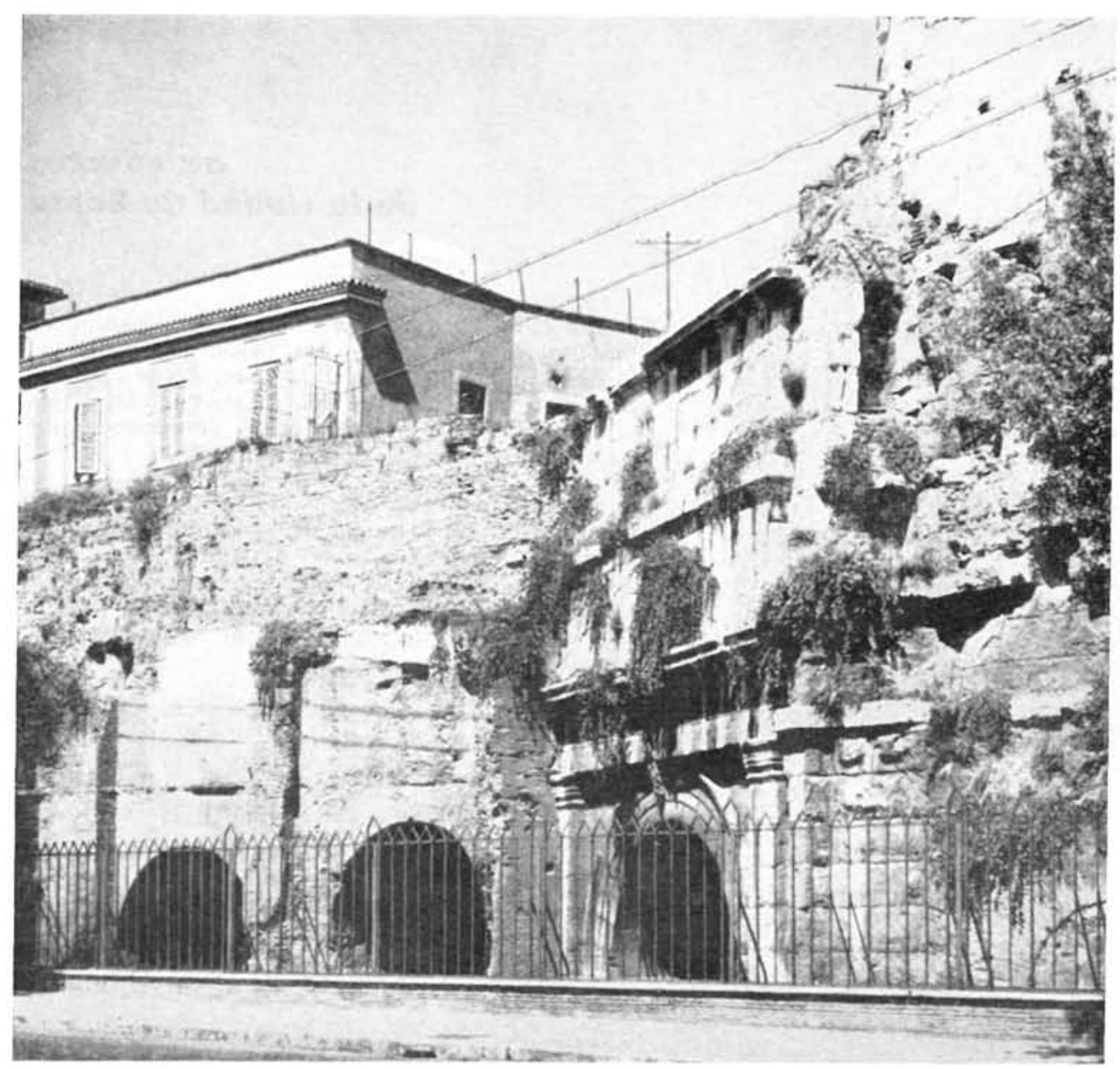

Las tres conducciones lia superpuestas en el empalme de Porta Ti. burtina. Según (107).

se incorporó a la de aquélla, después abandonaron ambas la canalización primitiva, construyéndose una nueva que llevaba el caudal total, si bien al llegar a Roma se volvían a separar, es decir, se hacía una partición en proporción de las aportaciones. En esta nueva traída, ambas conducciones superpuestas se montan sobre el acueducto final de la Marcia, que como ya hemos indicado tenía 9.578 metros.

Sigue a la anterior, en el mismo orden cronológico que venimos utilizando, el Aqua Virgo, que se realizó también por Agripa, inaugurándose en el año 19 a. de J. C., con recorrido de $20.875 \mathrm{~m}$, y una obra sobre arcadas de $1.036 \mathrm{~m}$. Todavía, durante el imperio de

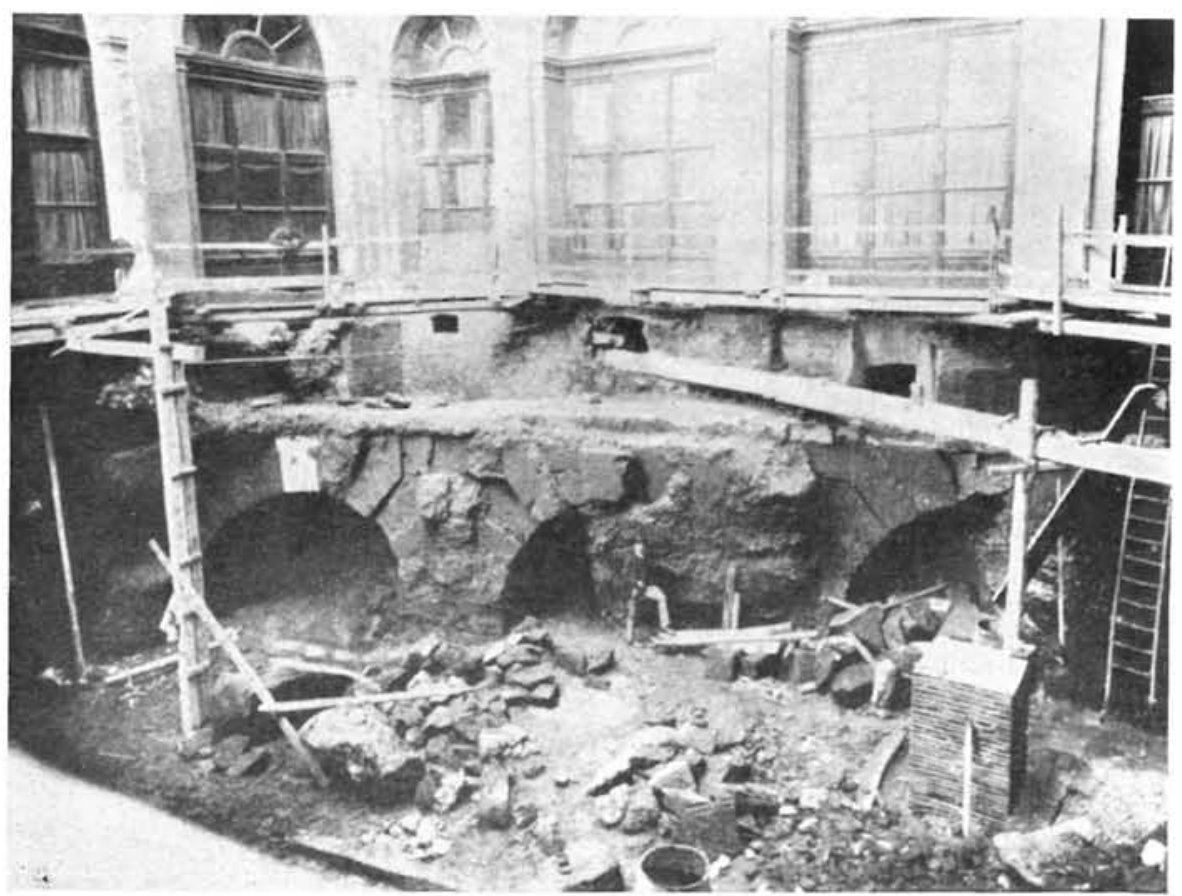

Restos de las arcadas del Aqua Virgo. Según (107). 

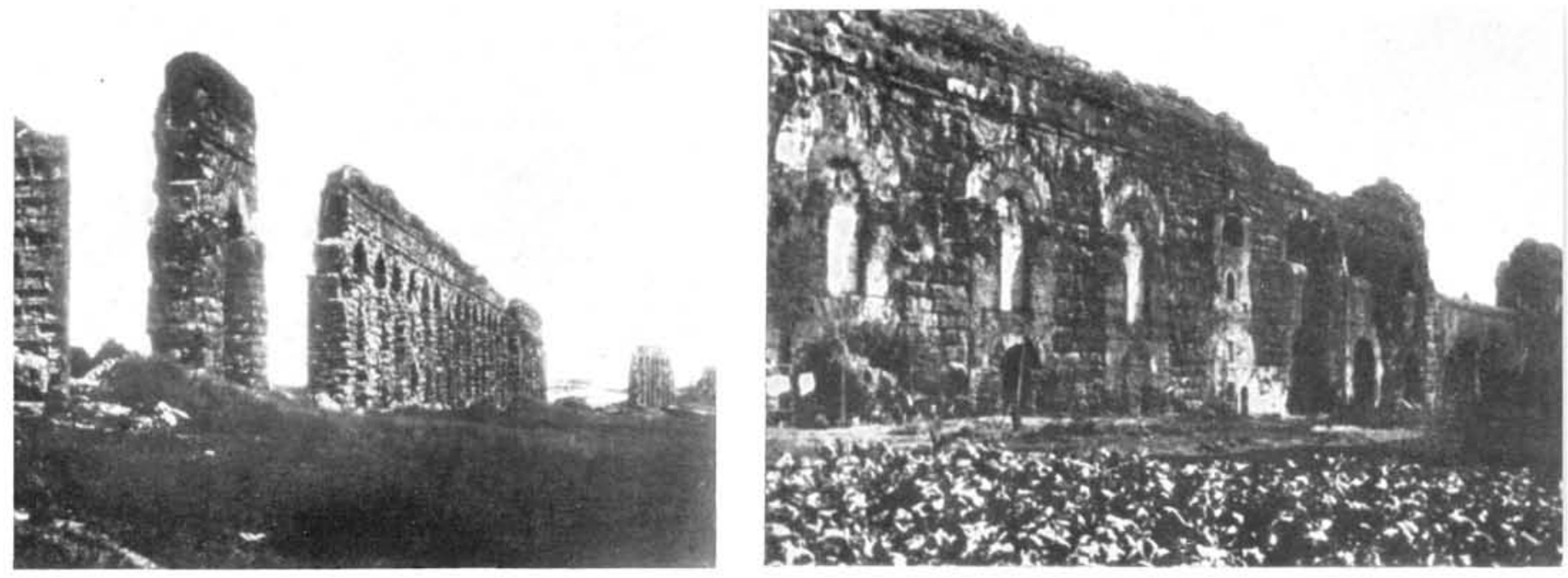

Restos del acueducto terminal del Aqua Claudia con los refuerzos de la restauración de los Severos. Superpuestos los restos de su canal y los de la Anio Novo. Según (102).

Augusto se hace una nueva traída de aguas, la Alsietina, con $32.814 \mathrm{~m}$ de recorrido y 530 en obra elevada, longitud que se repartía en acueductos aislados.

Tenemos después la Aqua Claudia, octava de las doce que aportaban sus aguas a Roma en la última época del Imperio. Se empezó por Calígula, en el año 38 a. de J. C., y se terminó por Claudio, en el 52 después de J.C., con toda magnificencia, teniendo un acueducto de $9.600 \mathrm{~m}$ que remataba los 68.680 del recorrido total. Esta conducción fue restaurada en múltiples ocasiones, la primera a los 30 años de servicio, por Vespasiano, y 10 años después, por Tito, aunque deben referirse a reparaciones en la zona alta subterrá. nea. El acueducto terminal, con cerca de $10 \mathrm{~km}$ de arcadas sencillas, todo en opus quadrata, ha dado fisonomía al paisaje de los alrededores de Roma en la zona correspondiente, y ha sido objeto de sucesivas modificaciones con obras de refuerzo en primera época, y de despojo vandálico después. Probablemente el miedo a la ruina por los efectos de los terremotos, determinó un refuerzo muy importante en época de Tito, primero, y de Septimio Severo y Caracalla, después. La primera consistió en el apeo de los arcos por otros interiores concéntricos, de fábrica de ladrillo, que reducen notablemente la luz ya reducida de origen, ya que, además, la fábrica de ladrillo se prolonga en pilastras adosadas a los pilares primitivos. Esto se complementó en ciertas zonas mediante arcos inferiores de apeo que transforman la ordenación de un solo piso de arcadas en otra de dos pisos. En la segunda reforma, que corresponde a los Antoninos, se macizó con obra de ladrillo el vano entero, dándose el caso curioso en las ruinas actuales, que de la opus quadrata queda sólo la impronta de sus sillares con su rústico almohadillado en la oppus lateritia del relleno posterior. En este acueducto es de gran interés un ramal construido en tiempo de Nerón dentro de la urbe, conocido por arcos neronianos o celimontanos, porque abastecían la zona próxima al monte Celio, terminando en el templo de Claudio, con un recorrido de unos $2 \mathrm{~km}$ en arcada simple y doble, trayecto que hoy día está casi todo en pie. Este ramal se restauró en diversas ocasiones por los Severos y se prolongó hasta el Palatino por Domiciano, también con doble arcada de ladrillo. En esta conducción hay, además, un acueducto de arcadas dobles con cinco arcos superiores y tres inferiores, pero es de los Severos.

Empezada también por Calígula y terminada por Claudio, tenemos la conducción del Anio Novo, que se tomaba del mismo río Anio, calificándose entonces de nueva ésta y de vieja la anterior, que ya hemos indicado. Tiene $86.876 \mathrm{~m}$ de longitud, pero, en la zona final, su canal quedó superpuesto al de la Claudia, utilizando el mismo acueducto terminal.

La conducción Trajana, para servir a la región Transtiberina, recogía tres aportaciones con longitudes hasta de $11.700 \mathrm{~m}$, y tenía luego trayecto único de 32.500. La caja estaba construida en fábrica mixta de reticulada y ladrillo, y los acueductos, que son siempre de pequeña altura, a excepción del que salva al Valle de la Trave, en fábrica de ladrillo. El Aqua Alejandrina, que viene a continuación y es la última, se debe al emperador Alejandro Severo, en 226 d. de J. C. Tiene varios acueductos de arcos elegantes en uno o dos pisos, como el del Valle de la Marranella, con 52 arcadas. 


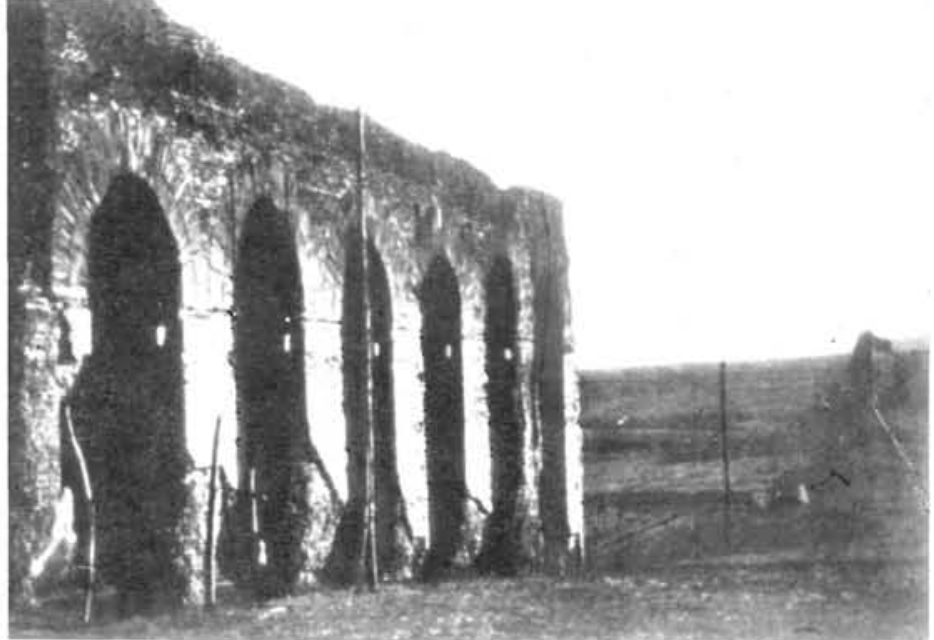

Restos de arcadas del Aqua Trajana en el valle de La Trave.
A partir de la construcción del ramal de la Claudia donde están los arcos neronianos o celimontanos, todos los acueductos o reparaciones de los anteriores que se acometen son de fábrica de ladrillo.

Con respecto a nuestro tema de los acueductos españoles, tiene interés el estudio de los acueductos de la ciudad de Roma, que pueden servir de pauta cronológica para la fijación de fecha en los nuestros, tan huérfanos por falta de documentación. Hay que prescindir de los construidos durante la República, pues está claro que en dicha época no iban a invertirse los caudales del erario público en beneficio de ciudades en comarcas no incorporadas definitivamente. En cambio, durante el Imperio, uno de los problemas que se plantearon en primera época fue este de la incorporación, transformando las poblaciones de rurales en urbanas, y uno de los medios más eficaces fue el de proporcionarles las ventajas de este tipo de vida a través de obras públicas utilitarias, de las cuales, la que más directamente afecta al ciudadano, es la traída de aguas.

Tenemos así el recuerdo de los emperadores constructores, lo que nos da una clave para proponer atribuciones en obras cuyos antecedentes directos se desconocen. Este criterio y el de las referencias directas de fábricas y detalles estilísticos de las propias construcciones, son los únicos caminos para la cronometría de las mismas. Además, cada país tiene su grupo de emperadores benévolos por diversas razones, la primera de las cuales es la cuna; así, en España tenemos a Trajano y Adriano; el primero, además, gran constructor de obras públicas, y el segundo, un apasionado de la arquitectura, a la que contribuyó directamente en los edificios y urbanizaciones de la villa Adriana y en otras obras importantes, como el Panteón y el templo de Venus en Roma. En España tenemos también como favorecedor a Augusto, que estuvo en ella cuando las guerras cántabras, que le ocuparon muy personalmente, pues con la terminación de las mismas inauguró su etapa de paz en el Imperio. (Pax Augusta).

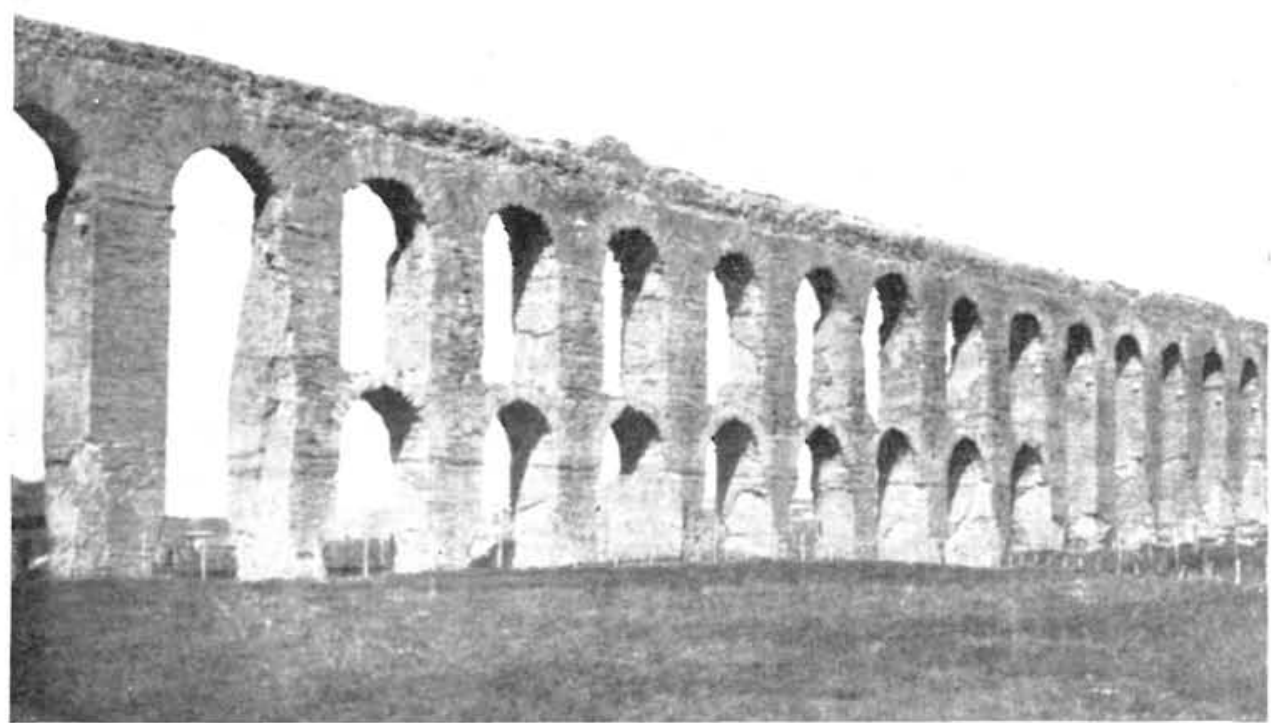




\section{acueductos españoles}

Para el estudio de los acueductos españoles no poseemos datos fidedignos ni referencias de época que nos orienten en su cronología. Tenemos que recurrir, como acabamos de indicar, a los métodos deficientes de las particularidades estilísticas y de examinar las épocas favorables de protección imperial. Nos contentaremos con hacer una ordenación sucesiva, complementada con hipótesis más o menos verosímiles para referir al emperador correspondiente cada uno de ellos.

Vamos a estudiar con algún detenimiento nuestros cuatro acueductos monumentales: Tarragona, Segovia y los dos de Mérida, Milagros y San Lázaro, de los cuales hemos obtenido un cierto acopio de datos y réferencias. Después trataremos el conjunto muy interesante de acueductos de Almuñécar, que se conservan útiles en la actualidad, para dedicarnos como final a recoger todo lo que existe en la realidad y en los libros de los de Sevilla, Toledo, Chelva, Barcelona, Granada, Calahorra, Cádiz, Blanes, Ciudad Rodrigo, etc.

La idea del acueducto de una sola fila de arcadas es repetir con regularidad monótona el tema del puente con su bóveda sobre pilares, ya muy afinados en éste, y más al pasar a una construcción que no ha de sufrir los embates de la corriente. Incluso se conserva en alguno de ellos el tema del arquillo auxiliar de aligeramiento de tímpanos. En cambio, el agua aquietada en la caja que lo corona exige la rasante horizontal, que se impondría después al puente.

Esta necesidad de conseguir la horizontalidad al cruzar un barranco lleva al acueducto de dos pisos e, incluso, al de tres, con la idea de nivelar por etapas, idea que debió traducirse en el sistema construc tivo de subrayar la horizontalidad al ir coronando parcialmente la construcción en las cornisas de remate de pisos intermedios. Así tenemos en Tarragona y en Segovia, pero la idea fue evolucionando hasta terminar subrayando la verticalidad, con lo cual los pilares ordenan todo el edificio, los arcos quedan en segundo plano, y las cornisas de coronación de sus impostas se interrumpen entre cada dos pilares. Esto ocurre en los dos acueductos de Mérida, y especialmente en el de los Milagros, con sus pilares de planta cruciforme, que acentúan sus contrafuertes de arriba abajo. Menos acentuado en el de San Lázaro, donde el piso inferior sirve de basamento, todo de sillería toscamente almohadillada en arcos, enjutas y pilares, mientras que los pilares continúan de sillería para arriostrarse en el segundo piso por arcos de ladrillo. En el de los Milagros, sólo es de sillería un arco, el del primer piso en el vano central de los tres que están dentro del cauce del río Albarregas, cuyos pilares moldean basamentos con tajamares adosados en triángulo.

En los acueductos de Almuñécar tenemos las cuatro soluciones del problema que se ordenan en el sentido descendente de la corriente, ya que en este mismo sentido crece su altura.

El primer acueducto, el del Barranco de Torrecuevas, es un puente que soporta la caja, con sus arcos de medio punto ligeramente alzados sobre el terreno, y los tímpanos partidos por los arquillos de aligeramiento. El segundo que, con los dos restantes, forma serie en tres barrancos sucesivos cada vez más profundos, es una fila de arcadas con sus arcos y pilares escuetos; en el segundo de esta serie los arcos tienen la misma luz, pero sus pilares son de mayor altura y quedan arriostrados por un nivel inferior de arcos que se intercalan como si se hubieran añadido después por precaución ante la excesiva esbeltez, mientras que en el último acueducto la parte inferior se nivela en un primer piso que forma como un muro a su vez aligerado con arcos de luz menor, sobre el que arrancan los pilares que soportan arcos de la luz normal, los cuales se continúan a ambos lados en arcadas directamente apoyadas sobre el terreno.

En los dos primeros acueductos mencionados, Tarragona y Segovia, tenemos el mismo tipo de fábrica opus quadrata, asentada a hueso, sin núcleo interno de hormigón ni conglomerante alguno entre los sillares, mientras que en los de Mérida los sillares, también asentados a hueso, dejan un espacio interno relleno con opus cementiciae. El almohadillado, cuando existe, se limita por plano en espesor y se recerca en todo el contorno con regularidad.

La terminación de paramentos en Segovia es más expresiva por el abultamiento del almohadillado, y la altura de hiladas difiere menos que en Tarragona. En éste, las dovelas tienen un paramento notablemente más liso que el resto de la fábrica, siendo siempre su estereotomía bastante regularizada. El número de dovelas oscila de 19 a 21 . Existen dos tipos de arenisca que a veces se alternan contrastando en textura y color. Su aspecto es idéntico al de la fábrica del llamado Pretorio en la ciudad, pues es contemporáneo. Las molduras que acentúan todas las separaciones entre elementos diferentes y subrayan la coronación por pisos son muy toscas en Tarragona y mucho más afinadas en Segovia, pero donde la diferencia resulta verdaderamente importante es en los pilares inferiores, pues el aumento de sección que en ambos se realiza por escalonamientos de sus dos dimensiones hace esbeltos a los segovianos, mientras que da una gran tosquedad a los tarraconenses.

En Mérida se tiene un dominio perfecto de la estereotomía especialmente en el de los Milagros, con la acentuación del contrafuerte, en el cual los sillares están más normalizados. Los arcos no son de medio punto, ya que, aunque el intradós arranca teóricamente a nivel del diámetro horizontal que subraya una cornisa, su boquilla no se desarrolla de un modo total hasta no independizarse de los pilares, existiendo unos triángulos iniciales con hiladas de sillares o ladrillos dispuestos horizontalmente, de tal modo que estas zonas de arranque más bien constituyen salmeres que trozos del arco propiamente dicho. Cuando se trata de arcos de piedra, estos salmeres proceden de sillares horizontales que penetran dentro del pilar. Los verdaderos arcos, sean de piedra o de fábrica de ladrillo, resultan así arcos rebajados como en el puente de Alconétar. 


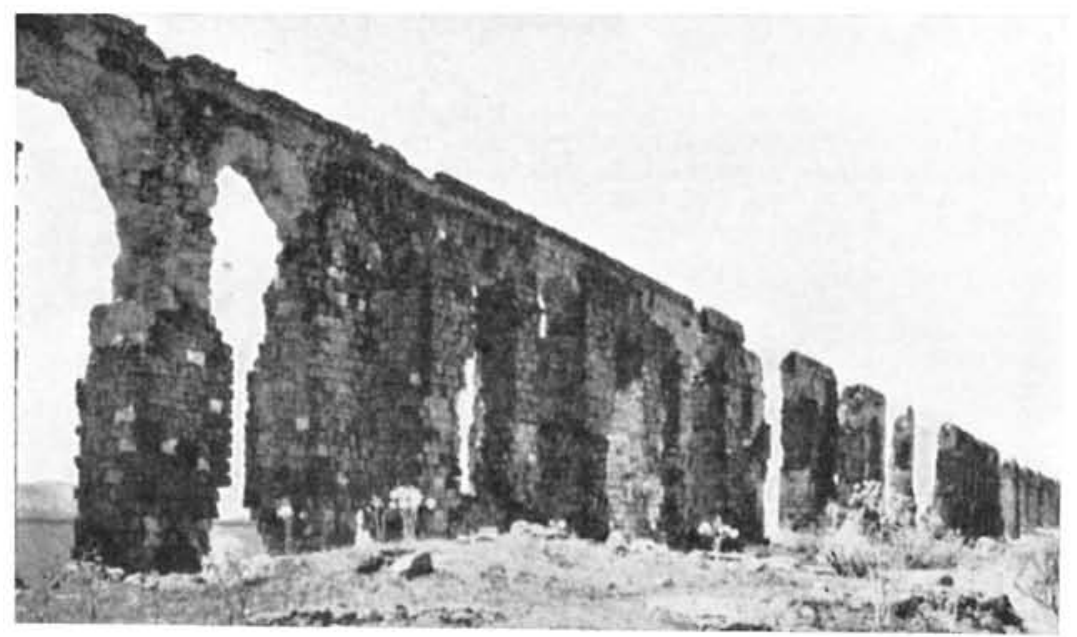

Acueducto de Túnez. Según (109).

En Mérida tenemos, además de la fábrica de ladrillo en los arcos, la intercalación de la misma en fajeados horizontales de los pilares que atraviesan en todo el plano horizontal el cuerpo del pilar. Estas hiladas decorativas y de ajuste de niveles y trabazón de paramentos es la única concesión a la opus lateritiae en estos monumentales acueductos, cuando ya en los de Roma esta fábrica había eliminado definitivamente a la opus quadrata. También hay que citar el carácter evolucionado de sus molduras.

En España se emplea poco la fábrica de ladrillo en la construcción de puentes y acueductos, aunque entre los primeros pueden citarse el de Carmona, el de Alnázcollar, etcétera, y en los segundos, el acueducto de Sevilla, conocido por el nombre de Arcos de Carmona, que corresponde a una conducción que viene de las proximidades de Alcalá de Guadaira, primero enterrada, luego sobre muro y después en largas alineaciones de arcadas de un solo piso, algunas de las cuales se conservan íntegras. Al llegar a la zona urbanizada desaparece, pues ha sido destruida por las edificaciones, conservándose un trozo reconstruido con dos pisos de arcadas, que tienen los tímpanos aligerados.

La fábrica de los acueductos de $\mathrm{Al}$ muñécar es muy pobre, lajas de pizarra, tanto en bóvedas como en pilares. Pero su riqueza expresiva supera esta limitación $\mathrm{y}$, por ejemplo, las molduras, que son simplemente de hiladas en saledizo, superponen una, dos o tres, según la importancia de su función, e incluso son de dos vuelos, según la importancia del elemento que coronan.

Por las razones que hemos apuntado, creemos que el orden cronológico de los cuatro acueductos prin-
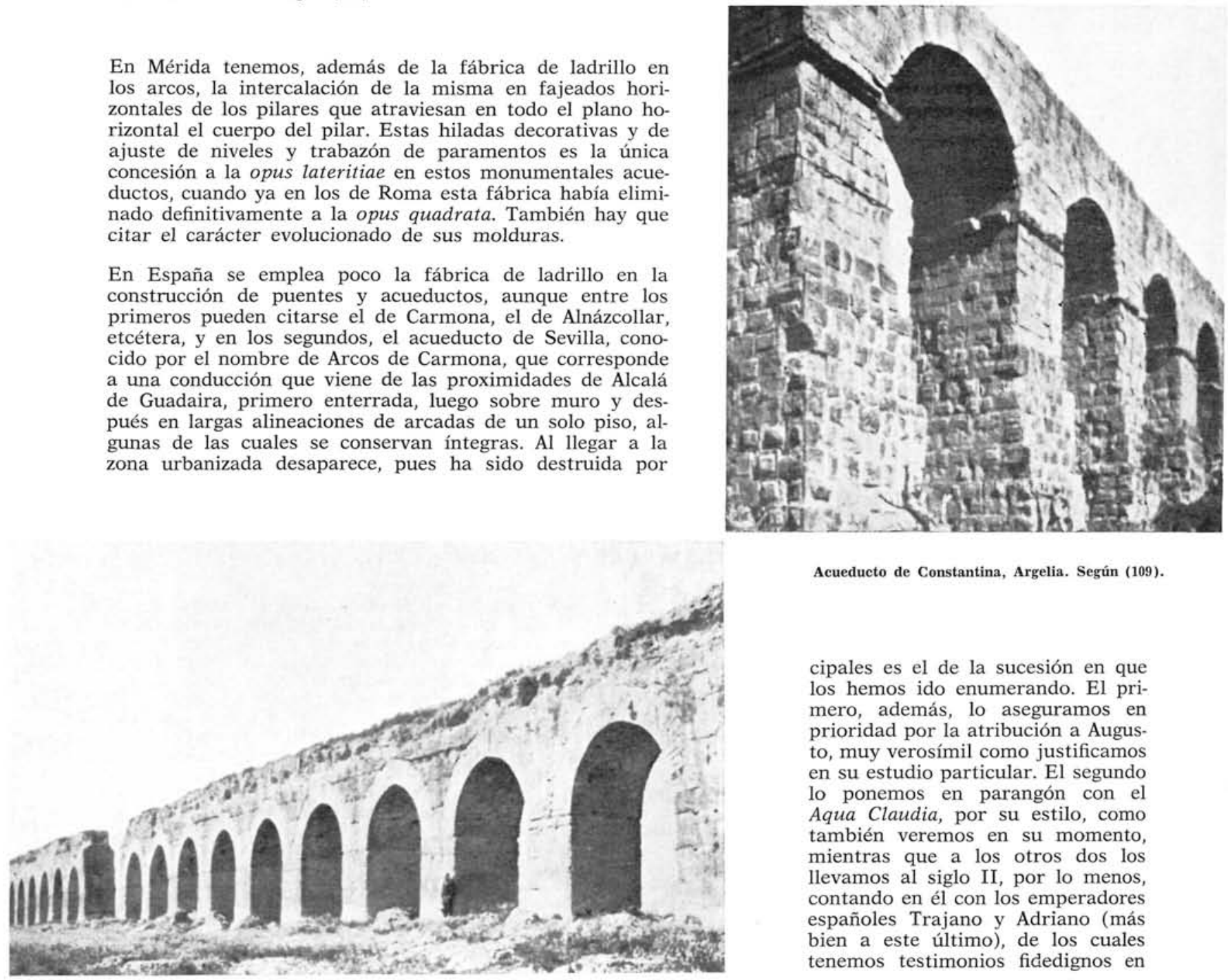

Acueducto de Constantina, Argelia. Según (109).

cipales es el de la sucesión en que los hemos ido enumerando. El primero, además, lo aseguramos en prioridad por la atribución a Augusto, muy verosímil como justificamos en su estudio particular. El segundo lo ponemos en parangón con el Aqua Claudia, por su estilo, como también veremos en su momento, mientras que a los otros dos los llevamos al siglo II, por lo menos, contando en él con los emperadores españoles Trajano y Adriano (más bien a este último), de los cuales tenemos testimonios fidedignos en 


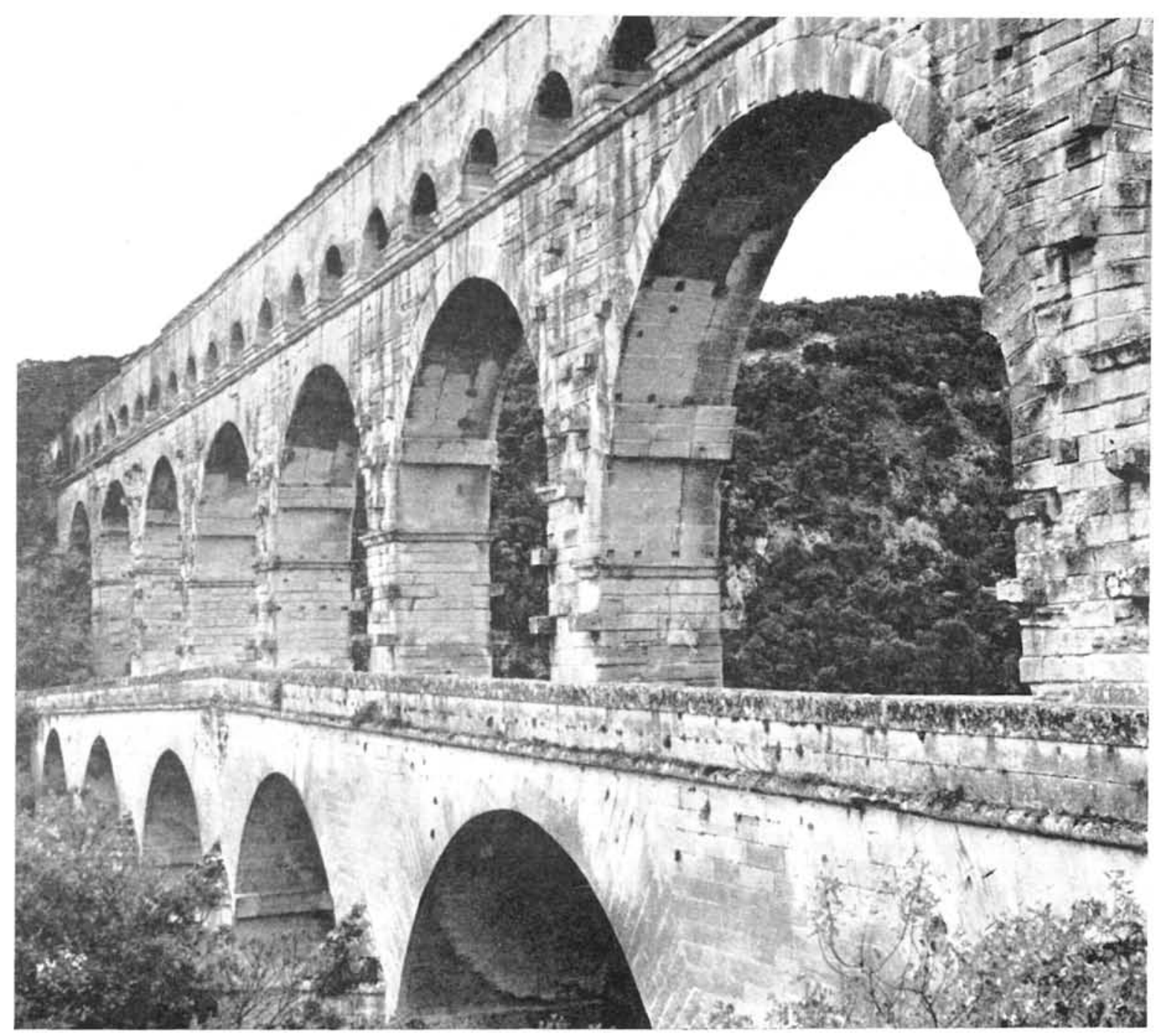

Vista del acueducto de Pont du Gard con la adición del puente construido en el siglo XVII ocultando las arcadas inferiores romanas. Según (108).

España, o bien más allá en la época de los Severos, que fueron constructores de obras públicas en algunas provincias del Imperio.

Creemos que el primer acueducto donde se emplé el artificio de la superposición de arcadas es precisamente el de Tarragona, que debió construirse al final de los años 20 a. de J. C., que corresponden al intervalo entre las conducciones de Roma, Julia (-33) y Virgo (-19); parece ser ligeramente posterior el Pont du Gard, del abastecimiento de Nimes, que es el más monumental y el de luces máximas en este tipo de construcciones. Lo encontramos después en Roma por vez primera en los arcos neronianos, adicionados al Aqua Claudia, y se repite después en las construcciones de Flavios y Severos, pero siempre con arcos de ladrillo. En las provincias romanas tenemos muestras abundantes, como Efeso, Patras, Chelles; y en España, en los más importantes: Tarragona, Mérida, Almuñécar, Toledo, etc. El de los Milagros, de Mérida, es de tres pisos, así como el Pont du Gard, aunque en éste los arcos superiores son de luz mucho más reducida. El de Toledo pudo ser también de tres pisos y, sin duda alguna, de dos.

\section{acueductos en otras provincias romanas}

Se han estudiado muy poco los acueductos romanos, a excepción de los de la ciudad de Roma, que tienen tres tratados monográficos importantes (101), (102) y (103). Hemos procurado reunir toda la información existente sobre los construidos en otras provincias romanas, con el objeto de relacionarlos con los nuestros para sacar de ellos toda la utilidad posible, por lo cual las referencias aparecerán cuando corresponda. En el artículo de hoy nos referimos al conocido por: Pont du Gard, que hace competencia al de Segovia por monumentalidad y buen estado, y que hemos de poner en relación muy directa y en competencia con nuestro acueducto de Tarragona. 


\section{acueducto de Tarragona}

\section{conducción de aguas}

Este acueducto, conocido por "puente de las Ferreras», al denominarse así el barranco que salva y por el apelativo frecuente en estos monumentos de "puente del diablo", servía al abastecimiento de Tarraco, hoy Tarragona, llevando el agua del río Gayá desde Pont d'Armentera, cerca del monasterio de Santas Creus, y a $10 \mathrm{~km}$ al E. de la ciudad. La conducción se desarrolla por el valle del Francolí, pasando por Villarodona y Vallmoll, y por el Fuerte del Olivo cerca de la ciudad, penetrando en ella por la llamada Falsa Braga del recinto amurallado, en cuya entrada se conserva un resto del mismo, dividiéndose allí en dos ramales, de los cuales uno iba hacia la ciudad alta, y el otro hacia la ciudad nueva, según Schulten. Se conserva otro resto al N. de la ciudad, junto a la fuente de los "Cuatro Algarrobos», a unos $250 \mathrm{~m}$ al E. de la carretera de Valls.

El canal se desarrolla en trinchera y a trechos en túnel, no existiendo otra obra de arte que la del acueducto que tratamos, el cual se encuentra a unos $4 \mathrm{~km}$ al $\mathrm{N}$. de la ciudad, a la vista y muy próximo de la carretera de Tarragona a Lérida.

\section{historia}

No hay dato alguno relativo a su construcción, ni siquiera acerca de su existencia en época romana. En cambio, es conocido por los geógrafos árabes, entre ellos Al-Makkari, que lo cita como ejemplo de los acueductos descritos por otro autor Ibnu-Ghalip, diciendo: «que conducía el agua desde el mar a la ciudad por una hermosa llanura y de un modo admirable sirvió para mover todos los molinos de piedra de la ciudad, siendo en conjunto uno de los más sólidos, magníficos y mejores de los monumentos hasta el presente construidos». Según referencia de Puig y Cadafall, de quien copiamos la cita anterior, fue restaurado en tiempos de Abderramán III, siendo muy visible en el monumento la obra correspondiente.

En los años 1781-90 se restauró toda la conducción, poniéndola de nuevo en servicio por los arzobispos de Tarragona J. de Santiyán y Valdivielso y D. F. Armañac, llevando la obra el arquitecto J. A. Rovira, quien, por su feliz actuación, fue nombrado académico de número de la Real Academia de San Fernando.

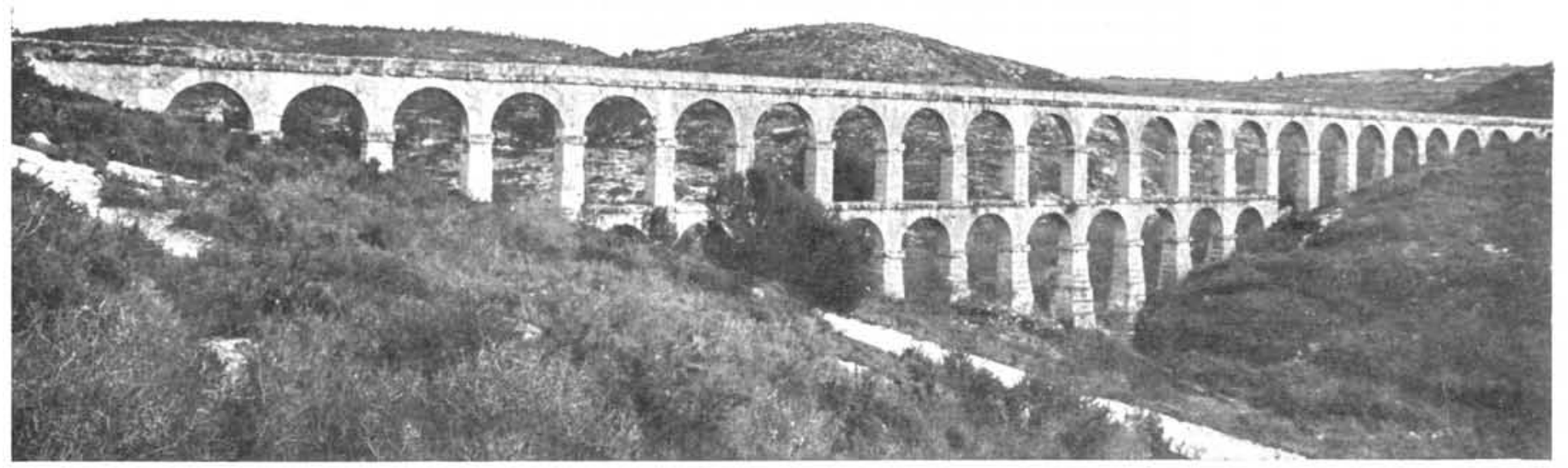

Vista desde la ladera derecha del barranco de las Ferreras. 


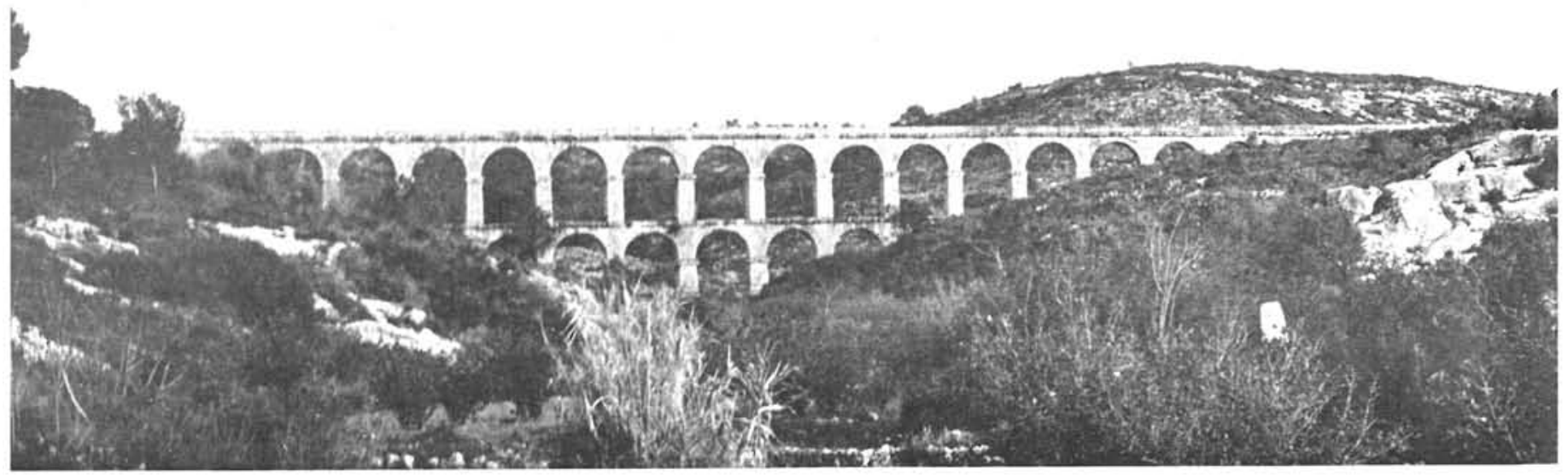

Vista desde aguas abajo.

En los años 1855 y 1856 la Comisión Central de Monumentos restauró el acueducto, atendiendo a su estado ruinoso, aunque de nuevo en el año 1880, a juzgar por la fotografía que ilustra el tomo relativo a Cataluña de la obra: España, sus monumentos y sus artes, tenía la caja completamente destrozada. En esta misma obra se da la referencia de que en dichas condiciones que hacían difícil el tránsito a pie a lo largo de la coronación, por el vértigo correspondiente a su gran altura en el centro, alguien apostó que lo pasaría a caballo, y lanzado a ello encontró un quiebro de la solera en la zona central, frente al cual el caballo se detuvo sin que le forzara a proseguir todo el tesón del caballero puesto en las espuelas y en la voz, por lo cual se apeó y le vendó los ojos, consiguiendo de este modo ganar la apuesta. También se atribuye esta hazaña de cruzarlo a caballo a la reina Isabel II cuando lo visitó. Hoy está interceptada la caja con sendas verias de hierro en sus extremidades para evitar el paso.

En las fotografías que se publican en el libro ya citado de Puig y Cadafall, que son de este siglo, siguen apareciendo destrozados los cajeros, así como una parte de la cornisa corrida del primer piso, pero hoy está completamente restaurado, existiendo dos muretes continuos de mampostería que forman caja en su coronación, absorbiendo los restos antiguos, que destacan por su color más oscuro.

Es monumento nacional número 874 .

\section{descripción}

La obra consta de dos pisos de arcadas, siendo 11 en el inferior y 25 en el superior, y se corona a una altura máxima de $26 \mathrm{~m}$, con una longitud total de unos $200 \mathrm{~m}$, en la que se cuentan las extremidades sobre muros.

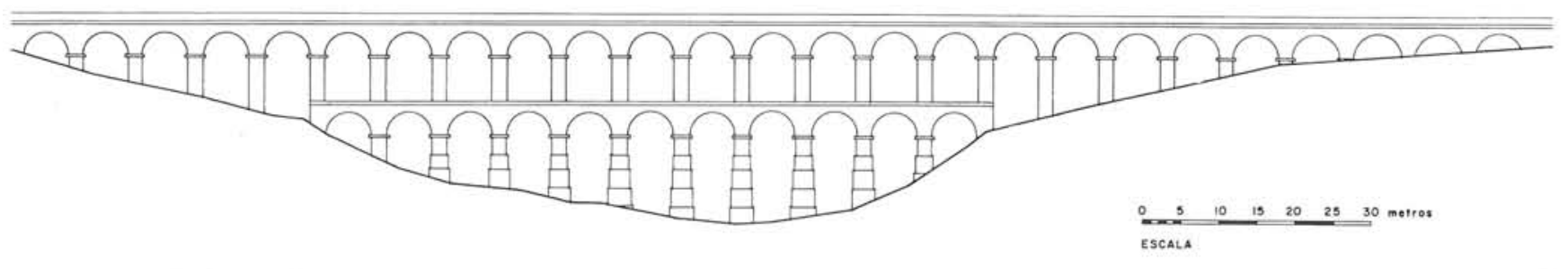

Alzado general. 
Los arcos son todos de la misma luz, 5,90, con irregularidades de $\pm 15 \mathrm{~cm}$ luz, que deben corresponder a 20 pies romanos, alcanzando la distancia entre ejes de pilares 7,95 $\mathrm{m}$, es decir, unos 26 pies.

Las luces de los arcos superiores se conservan en los inferiores, pero, en cambio, la anchura de las bóvedas aumenta ligeramente, ya que, descendiendo desde la caja, la latitud del monumento aumenta por escalones de medio pie, cada vez que se pasa por una de las cornisas que ordenan horizontalmente la superposición de elementos arquitectónicos.

El tramo anterior de canal excavado en la roca se enlaza con la caja del acueducto mediante fuerte curva y rápido desnivel sin regularizar una y otro, apareciendo en el fondo restos de opus signinum del revestimiento que continúa en todos los trozos de la caja antigua que existen sobre el acueducto.

Las bóvedas superiores con $1,86 \mathrm{~m}$ de anchura (6 pies) se despiezan en 19 ó 21 dovelas, destacando siempre una en clave y adosadas a hueso, con perfecta regularidad en los planos radiales de juntas. Las dovelas de arranque de cada dos arcos adyacentes forman un solo sillar pentagonal, especial mente cuidado y con labra más fina que los restantes. El trasdós de las dovelas se ajusta a las caras de los sillares de tímpanos, para lo cual las líneas horizontales correspondientes a las hiladas de estas zonas definen los vértices del contorno poligonal que recortan las dovelas en su trasdós.

Esto debió obligar al retoque de las dovelas ya colocadas cuando se procedía a colocar los sillares de tímpanos, existiendo algunas con entrantes especiales para recibir las salientes de los sillares correspondientes. En casi todos los arcos, las segundas dovelas, a partir de arranques, se prolongan para llegar al contacto con la simétrica del arco adyacente, que le había precedido, lo cual nos indica la dirección en que avanzaba la construcción. También se observa, aunque con menos frecuencia, esta misma disposición en las terceras dovelas.

El espacio de tímpanos se enjuta con cuatro o cinco hiladas de sillares que enrasan a nivel de trasdós de clave, corriendo una cornisa a todo lo largo de la obra, que se prolonga en las zonas terminales sobre muros. Esta cornisa es una hilada en voladizo, que da una simple moldura rectangular con menos altura que todas las demás (unos $48 \mathrm{~cm}$, que correspondería a 1,5 pies). Esta hilada se mantiene a nivel corrigiendo las irregularidades acumuladas hasta ella, debiendo quedar en normalidad tangente a claves, por lo cual se intercalan sillares de reducida altura, cuando esto no se logra; o bien, cuando la desviación es más pequeña, los mismos sillares de cornisa engloban este recrecimiento en un escalón de su paramento a haces con el plano vertical definitorio de bóvedas y tímpanos.

El festoneado de bóvedas se limita de modo análogo inferiormente por voladizo de la hilada superior del pilar, que forma de este modo cornisa, revolviendo por igual en las cuatro caras de éste. Esta cornisa resulta de altura igual a la hilada normal 60 centímetros.

Los pilares del piso superior son prácticamente iguales con sección de $2,05 \times 1,86 \mathrm{~m}(7 \times 6$ pies) y altura de $4,50 \mathrm{~m}$, descontando la cornisa de coronación. Sus fustes llegan a la coronación del piso inferior que se realiza también con una hilada completa destacada en voladizo por ambos paramentos, y con un espesor prácticamente igual al de la cornisa superior. Esta inferior no muere en el terreno, sino que revuelve en los pilares extremos de las 11 arcadas que constituyen el piso inferior, quedando cortados verticalmente los tímpanos de los últimos arcos. Al desaparecer los arcos intermedios, los pilares continúan con la misma sección, amoldándose en altura al terreno. Los últimos arcos superiores quedan sin pilares, arrancando finalmente de simples cornisas a nivel del terreno. La caja continúa por ambos lados sobre muros revestidos con opus incertum hasta empotrarse en ambas laderas.

En las bóvedas inferiores con sus enjutados se mantiene la misma estereotomía que en los superiores, aunque la anchura ha aumentado en 1 pie. En cambio, la morfología de los pilares cambia totalmente, pues se convierten en escalonados, después de un cuerpo superior de tres hiladas (5,5 pies aproximadamente) con fuste en los cuatro frentes, verificándose los escalonamientos cada dos o tres hiladas, hasta llegar, en los de mayor altura, a una sección en la base de $3,75 \times 3,08 \mathrm{~m}$ $(12,5 \times 10$ pies $)$, después de cinco escalonamientos y 14 hiladas. Los escalonamientos claves suelen ser de 1 pie. Al llegar al terreno no se aprecia ensanchamiento para formar un basamento en cimientos.

La caja que corona la obra, finalidad de la misma, ha sufrido restauraciones muy importantes, como atestiguan las fotografías que hemos indicado para las últimas. En la actualidad son dos muretes de mampostería directamente sobre la cornisa del segundo piso de arcadas, enlucidos interiormente en continuidad con el fondo. Los muretes son de 1 pie y dejan un espacio de 2,5 pies, aunque éste disminuye con el revestimiento de unos $2 \mathrm{~cm}$. Estos muretes han sido las partes más vulnerables a la acción destructora de bárbaros y gamberros de todas las épocas. Parece muy probable que, salvo la época romana y unos cortos períodos después de las reconstrucciones generales de la conducción, en el resto de su vida el acueducto no ha podido cumplir su misión. 


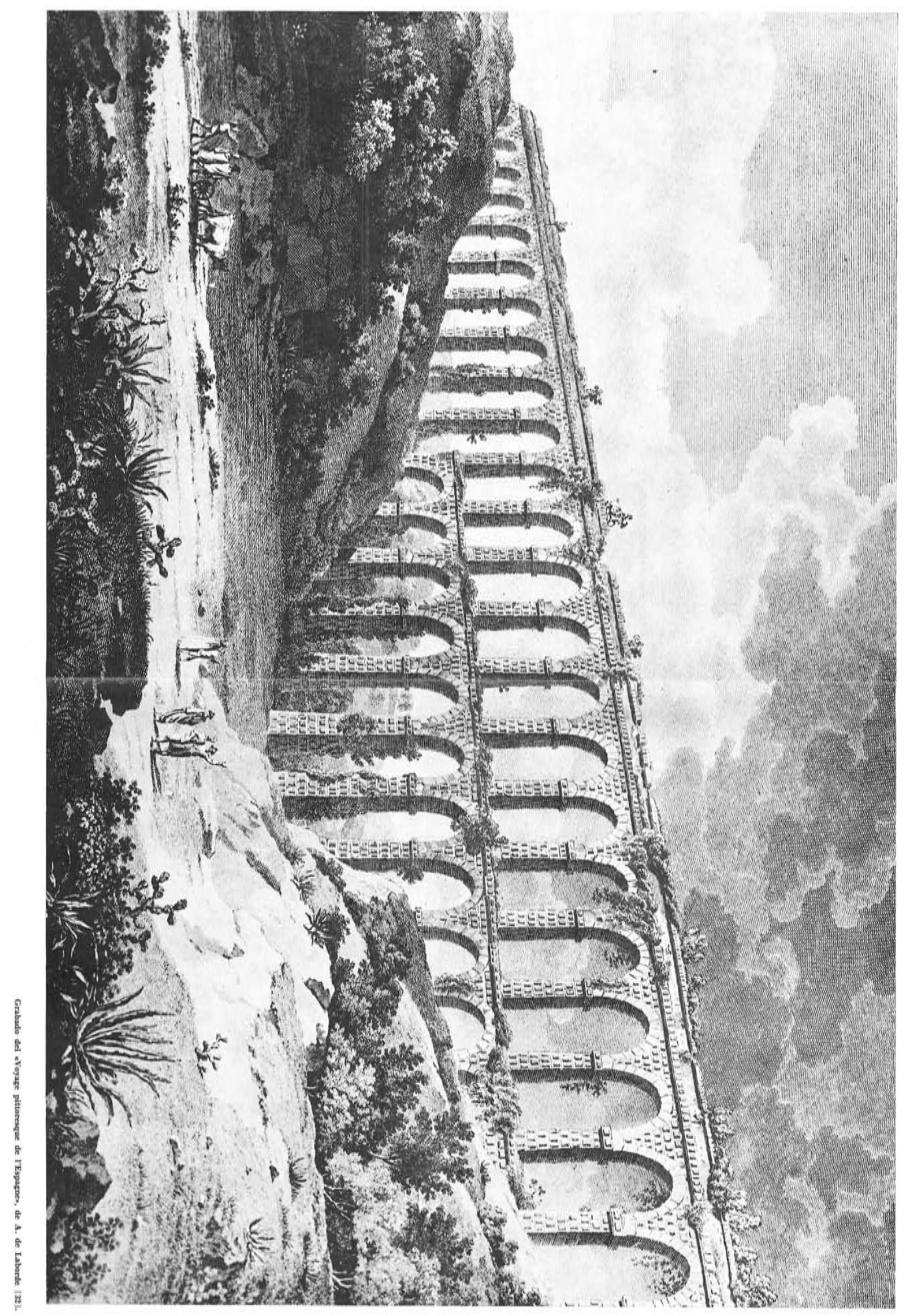




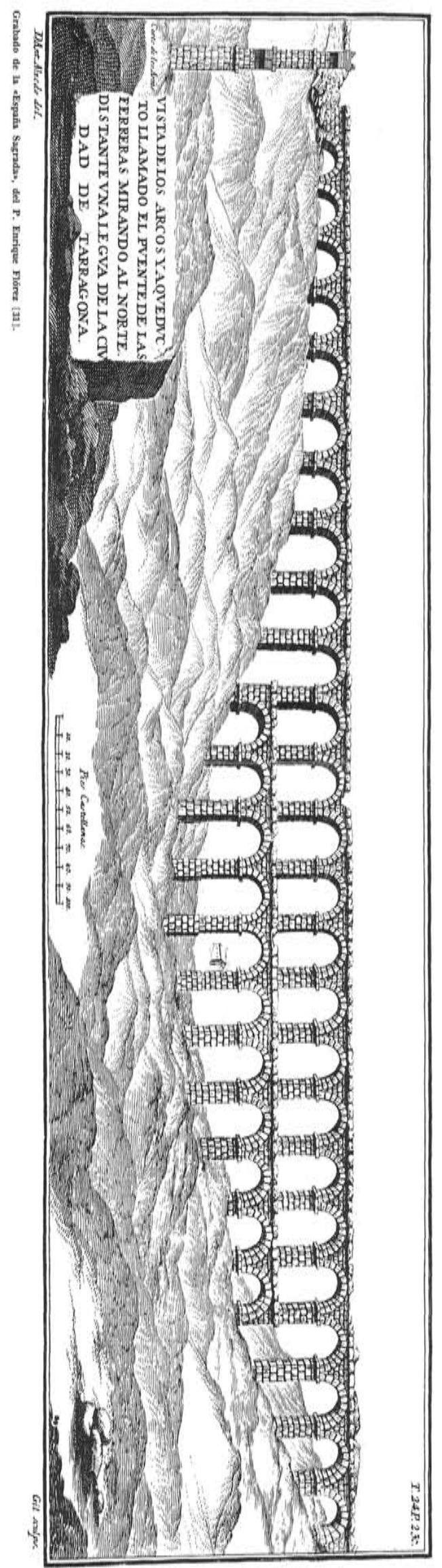

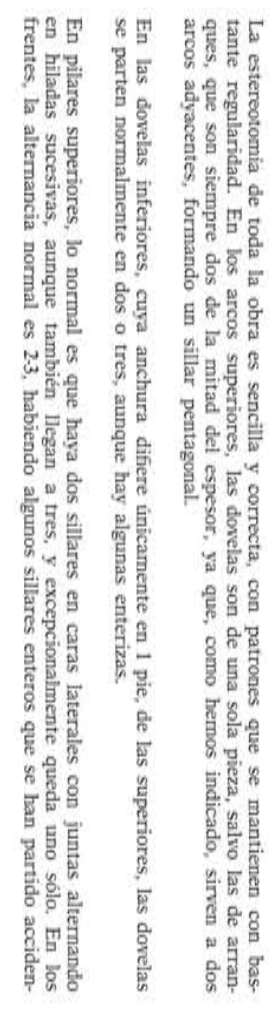
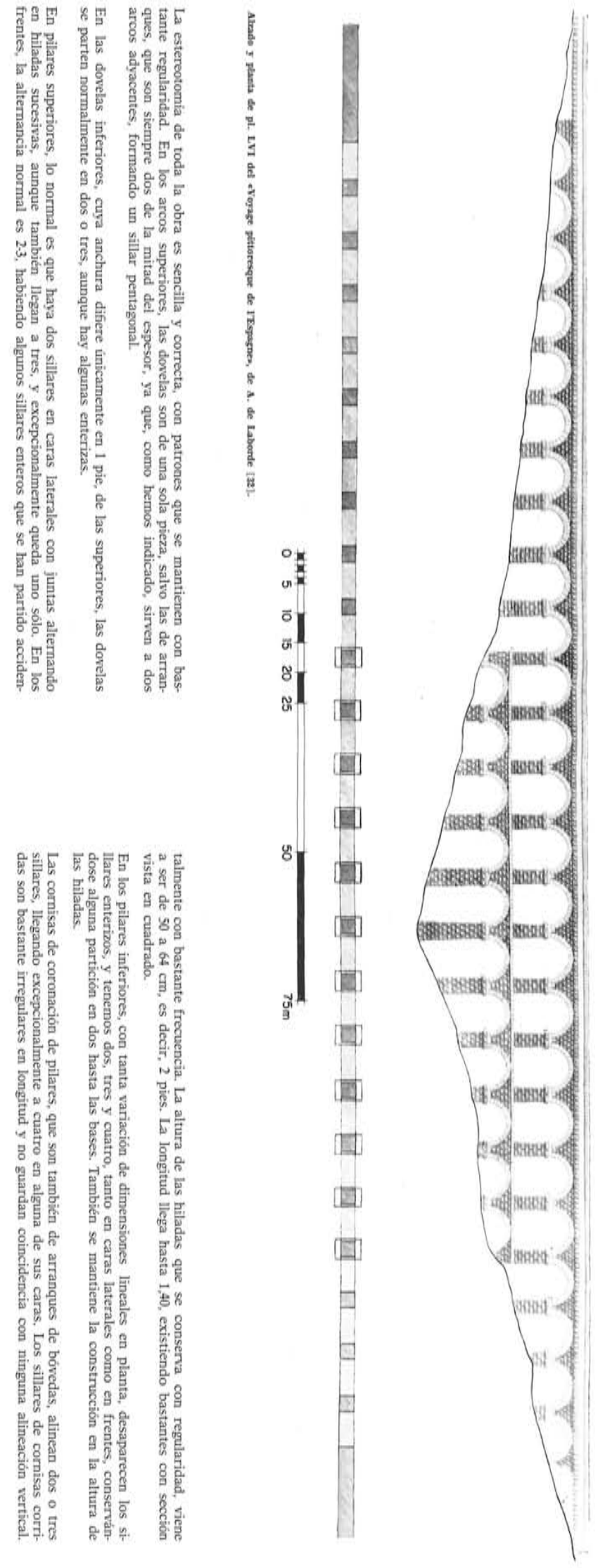


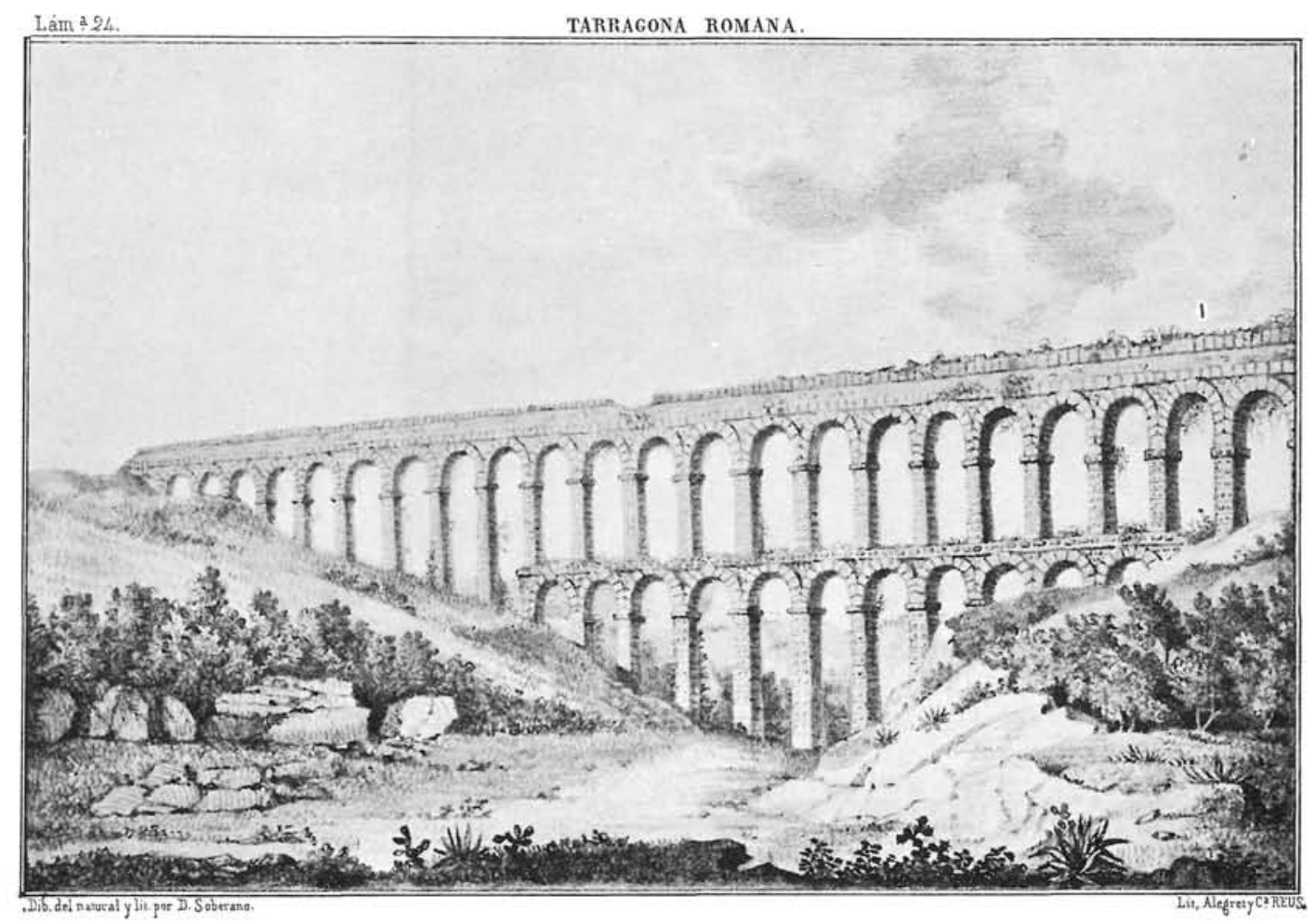

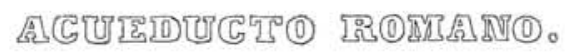

Litografía de la obra «Tarragona monumental» [34].

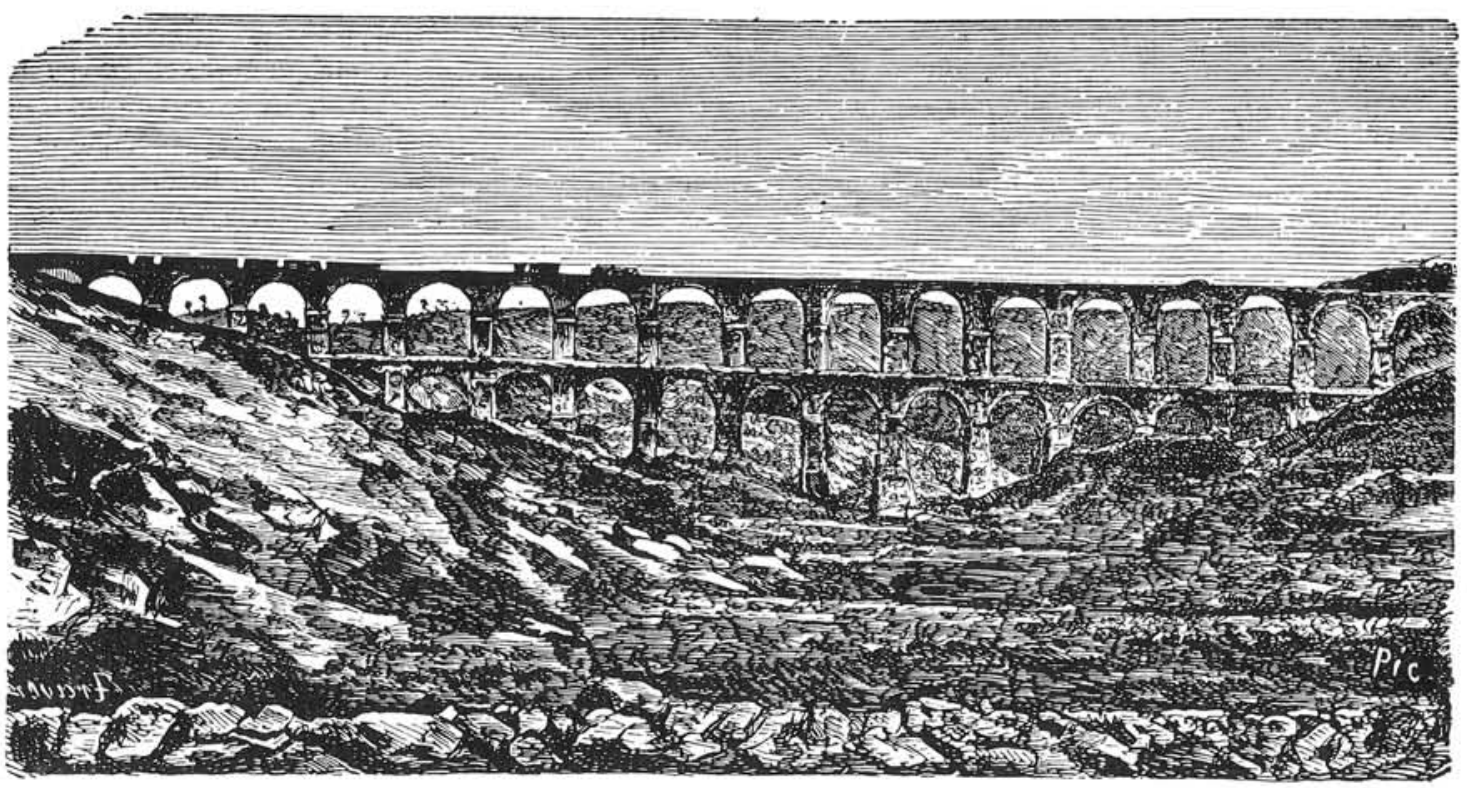

Acueducto de Tarragona.

Grabado de la obra «Crónica general de España» [35]. 


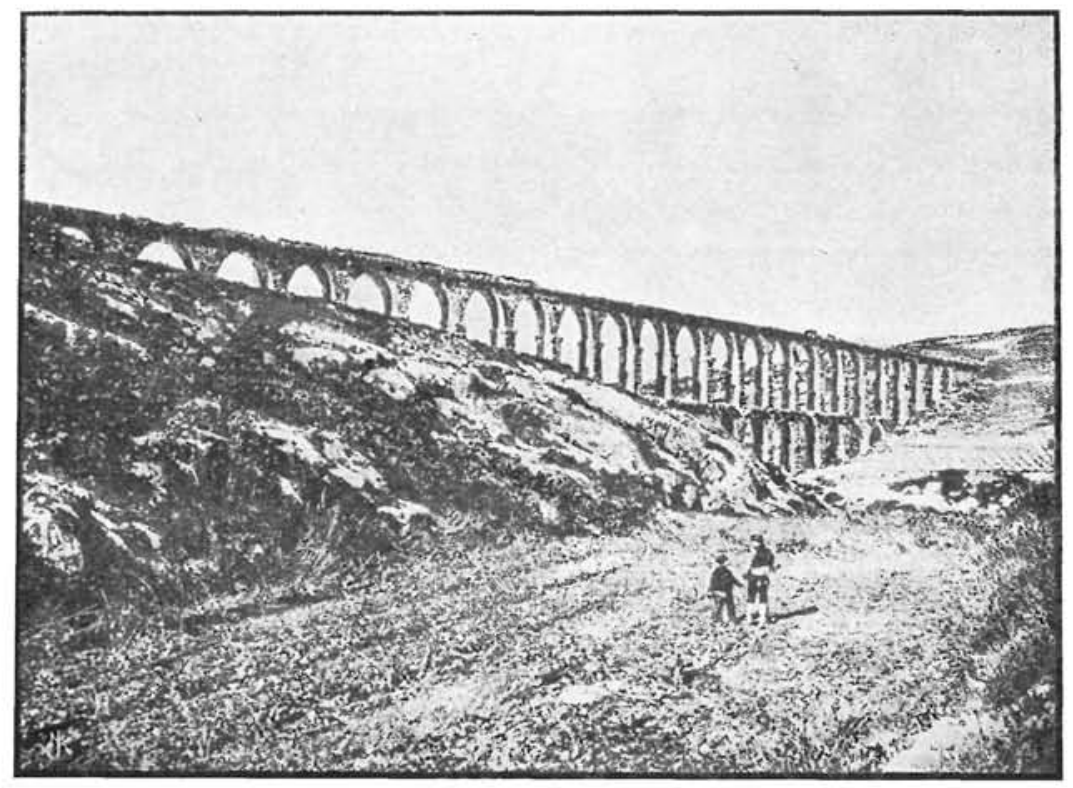

TARRAGONA.-ACCEdUCTO LLAMAdo dE LAS FERRERAS̀

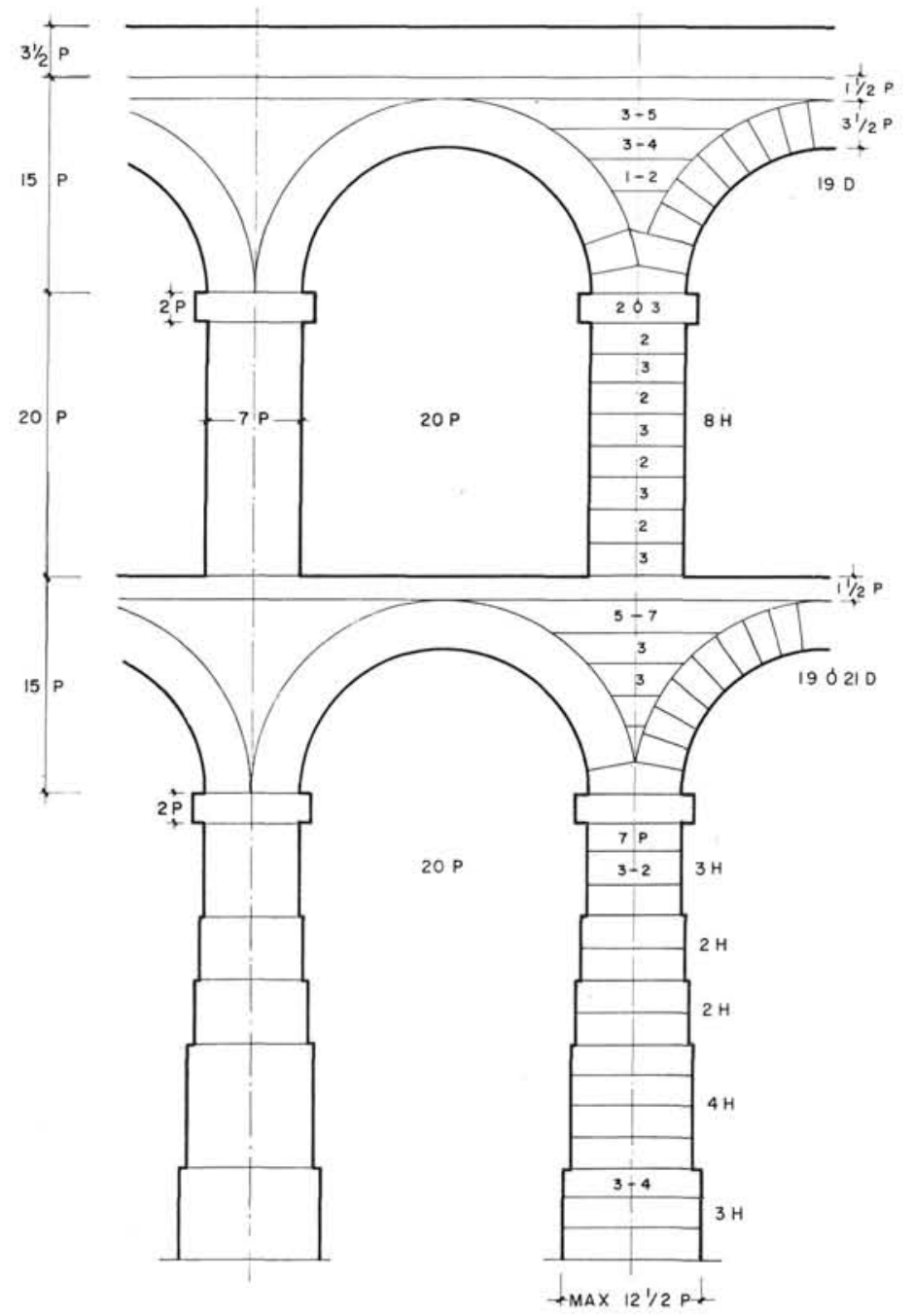

Fotograbado de la obra «Cataluña: sus monumentos y artesn [36].

Detalles de la estructura en alzado y sección vertical.

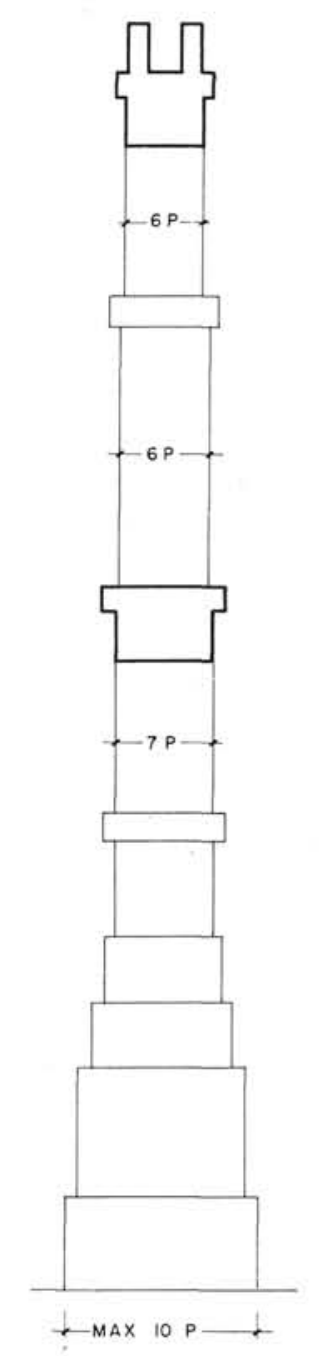




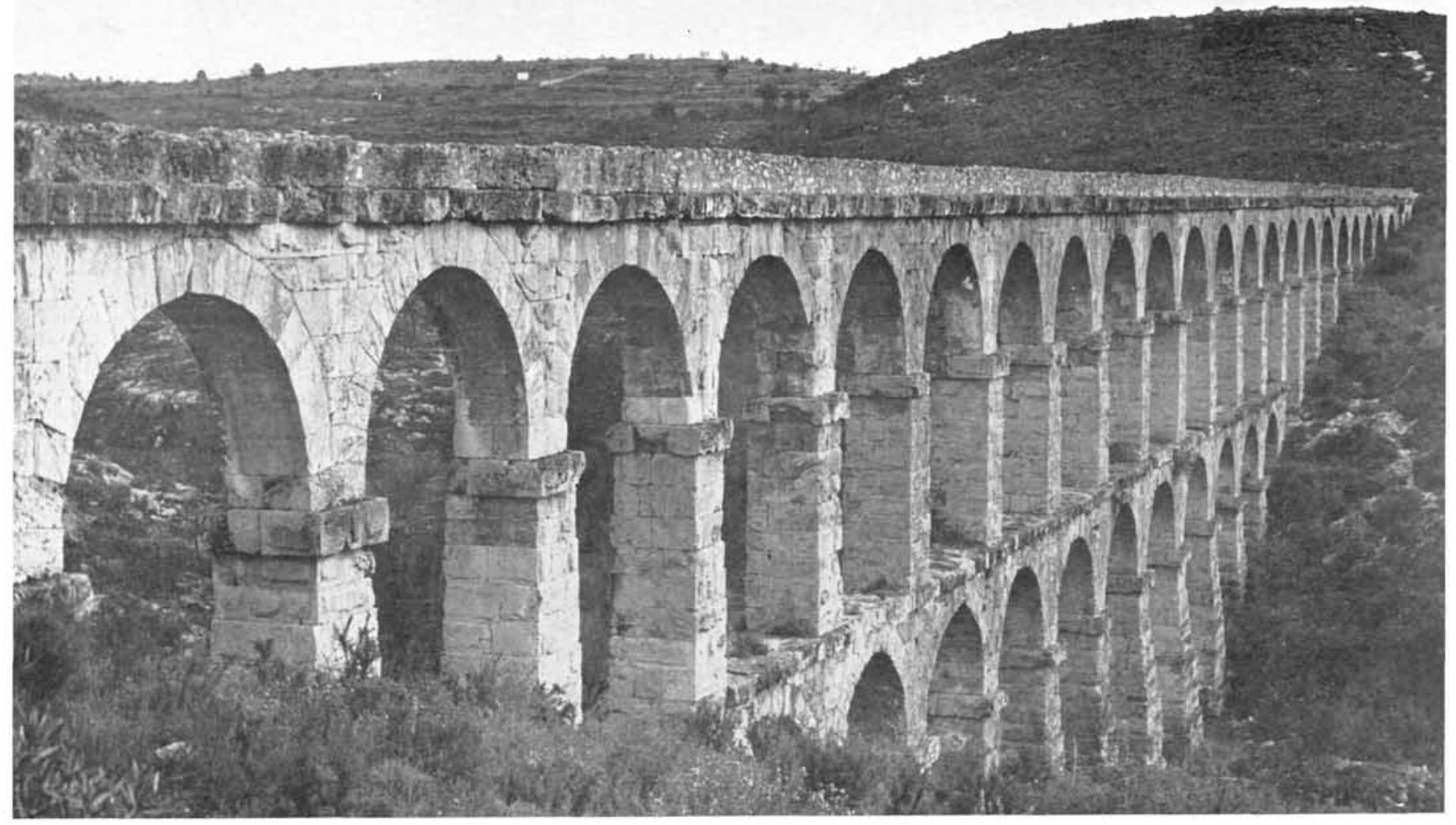

En cuanto a la labra de superficie, se observa mayor finura en las dovelas y especialmente en las de arranques comunes a dos arcos adyacentes. Las enjutas de arcos inferiores aparecen también más planas que las de caras de pilares donde se observan dos tipos de labra: unas con almohadillado recercado y otras casi planas. De vez en cuando existen sillares con un almohadillado muy saliente, generalmente en caras cuadradas. Pero el almohadillado tiene la acentuación máxima en las cornisas, donde, como ya hemos indicado, las dimensiones son bastante irregulares, siendo algunas cuadradas. En ningún caso se observan sillares aislados en vuelo.

Vista en escorzo desde el fondo de barranco.

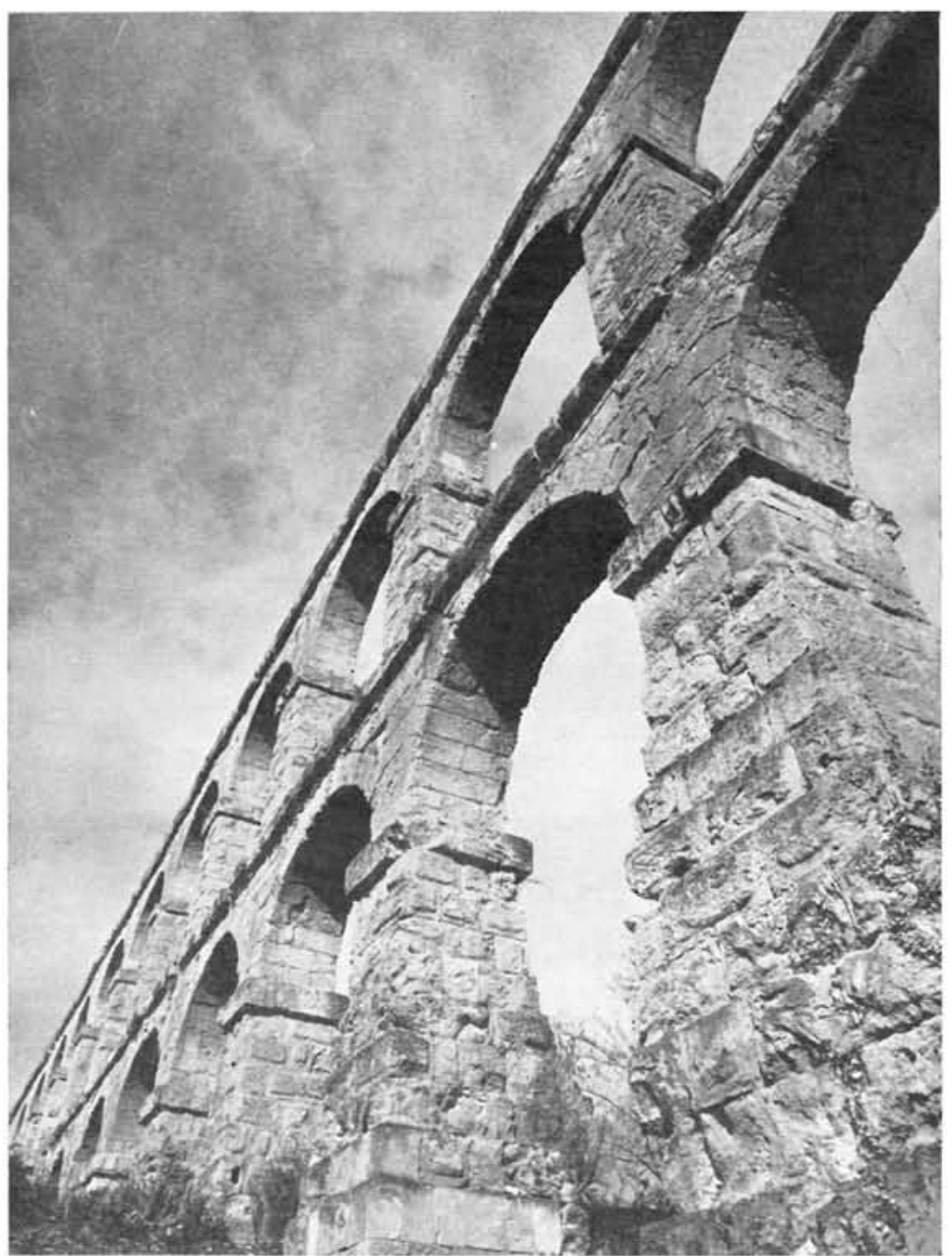


Los muros triangulares que encuadran la ordenación en arcadas son de opus incertum, con estructura cementiciae interna y con paramentos de mampuestos de canto rodado, más acusados que en la caja que los corona.

Entre todos los acueductos españoles que consideramos, es el de fábrica más sencilla (opus quadrata, sin opera cementiciae), y la luz de los arcos es la normal entre los de gran número de vanos. El diseño es clásico desde los primeros ejemplares de su especie, aunque los pilares inferiores con el doble escalonamiento tan repetido den una nota de tosquedad poco frecuente en obras de altura análoga. Esto es un detalle de falta de dominio (arcaísmo) en el proyecto básico, que se conjuga con el de simplicidad de las cornisas en lo que se refiere a detalles. La misma solución con una tosquedad todavía más acentuada, encontramos en el acueducto de Constantina y no en el de Cherchell, ambos en Argelia.

Recuerda en simplificación máxima y a escala reducida al Pont du Gard, que servía a la conducción para abastecimiento de Nimes, en el cruce de dicho río. Se dice que este acueducto fue el primero donde se utilizó la superposición de arcadas; está fechado, sin gran seguridad, hacia el 18 a. de J. C., y su construcción fue llevada a cabo por Agripa, el lugarteniente de Augusto.

En las distintas reparaciones se han encajado sillares enteros, se han rellenado los huecos de algunos con canto rodado y con ladrillos, y en los menos se ha enlucido el paramento con mortero de color rosa.

Es lógico que fuera Tarraco una de las ciudades más importantes en el comienzo del imperio romano, la primera que tuviera una conducción de aguas de importancia, y resulta muy verosímil que se lo deba directamente a Augusto, quien tuvo en ella su cuartel general cuando las guerras cántabras, en los años 26-25 a. de J. C., y la convirtió en capital de la provincia, honrándola con el sobrenombre de Triumphalis, en recuerdo de la feliz terminación de la campaña, quedando nuestra ciudad con la designación oficial de Colonia Julia Urbs Triumphalis Tarraco. César la había elevado al rango de colonia en el año 45 a. de J. C., inmediatamente después de la batalla de Munda, dándole el apelativo de Julia.

\section{problemas arqueológicos}

Salvo la remota referencia a la estancia de Augusto en Tarragona en 26-25 a. de J. C., que ha servido de base a la suposición que aventuramos al final del párrafo anterior, no encontramos dato ni noticia que nos permita datar el monumento.

La verosimilitud de nuestra atribución ha de apoyarse en razonamiento simple y en consideraciones breves sobre las características técnicas y estilísticas del monumento.

El razonamiento a que aludimos tiene como premisa el no situar la obra de la conducción antes del principado de Augusto, pues cuando la conquista de las provincias era la tarea a realizar fuera de Italia, la obra pública que corresponde es la calzada de penetración primero, y de consolidación después, del territorio que habría de construir el Corpus del Imperio. Mientras esto no fuera una realidad, no podía el Estado romano derrochar sus caudales en beneficiar algo no propiamente suyo. Argumento que se invierte en cuanto dicha realidad se consigue. El fin de las guerras cántabras puede ser el punto preciso de la transición, y en ese instante tuvo Tarraco una situación privilegiada.

En detalles estilísticos tiene el monumento toda la sencillez de la arquitectura de Augusto. Simplicidad por dominio de problemas técnicos, que por vez primera permiten sobriedad. Como hemos visto, la estereotomía está perfectamente regularizada.

El tema de la arcada se ha depurado a través de los puentes, puertas y arcos honoríficos, y en acueductos tenemos ya la gran obra del terminal de la Marcia, con su millar y más de arcadas. Pilares, bóvedas, tímpanos y cornisas recogen la experiencia de anteriores realizaciones y las interpretan del modo más escueto y estricto, sin molduras ni otras licencias decorativas. Incluso el almohadillado, que es la puerta de escape al expresionismo, acentuando en la rudeza del desbaste la fortaleza propia de la obra ingenieril, resulta contenido, al limitarse en superficies planas y recuadrarse mediante fajas de reborde uniforme y finamente labradas. Además, esta licencia se utiliza únicamente en los pilares, elementos robustos de la construcción, y en las cornisas, que dan la textura horizontal. Toda la apariencia de los paramentos, lo mismo en el despiezo correspondiente a la estereotomía, que en el terminado de las superficies, es idéntica a la de los monumentos tarraconenses de esta época, existiendo coincidencia perfecta, pues se ha utilizado la misma piedra. También podemos comparar la terminación de paramentos con otras obras ingenieriles de la misma época, el puente de Alcanlavill, en el trozo de vía romana de Hispalis a Gades.

Llevando nuestro razonamiento hasta el límite, damos a nuestro monumento la prioridad en el empleo de la solución de doble arcada. En Roma, este artificio no aparece hasta los arcos neronianos, que prolongan el Aqua Claudia hasta el templo de Claudio, y en provincias, el otro acueducto que puede disputarle la primacía es el Pont du Gard, que ya hemos citado. Resolvemos la pugna a favor del tarraconense por ser el problema más sencillo de resolver en él, sin río que lo complica extraordinariamente, y, además, la escala geométrica $230 \mathrm{~m}$ de longitud y 47,40 de altura, contra 200 y $26 \mathrm{~m}$, respectivamente. 

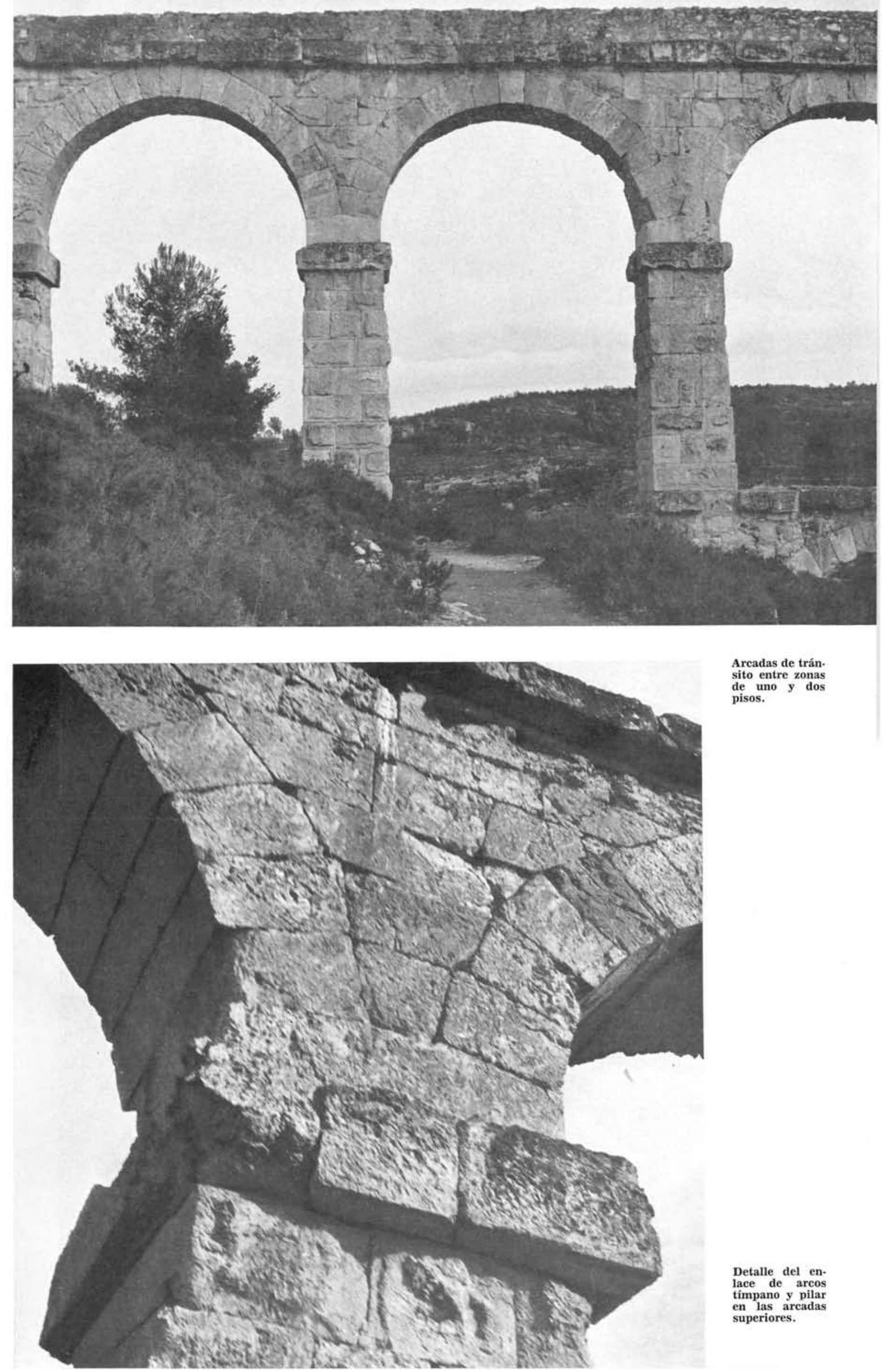

Arcadas de trán. sito entre zonas
de uno y dos pisos.

Detalle del en lace de arcos timpano y pilar en las arcadas 

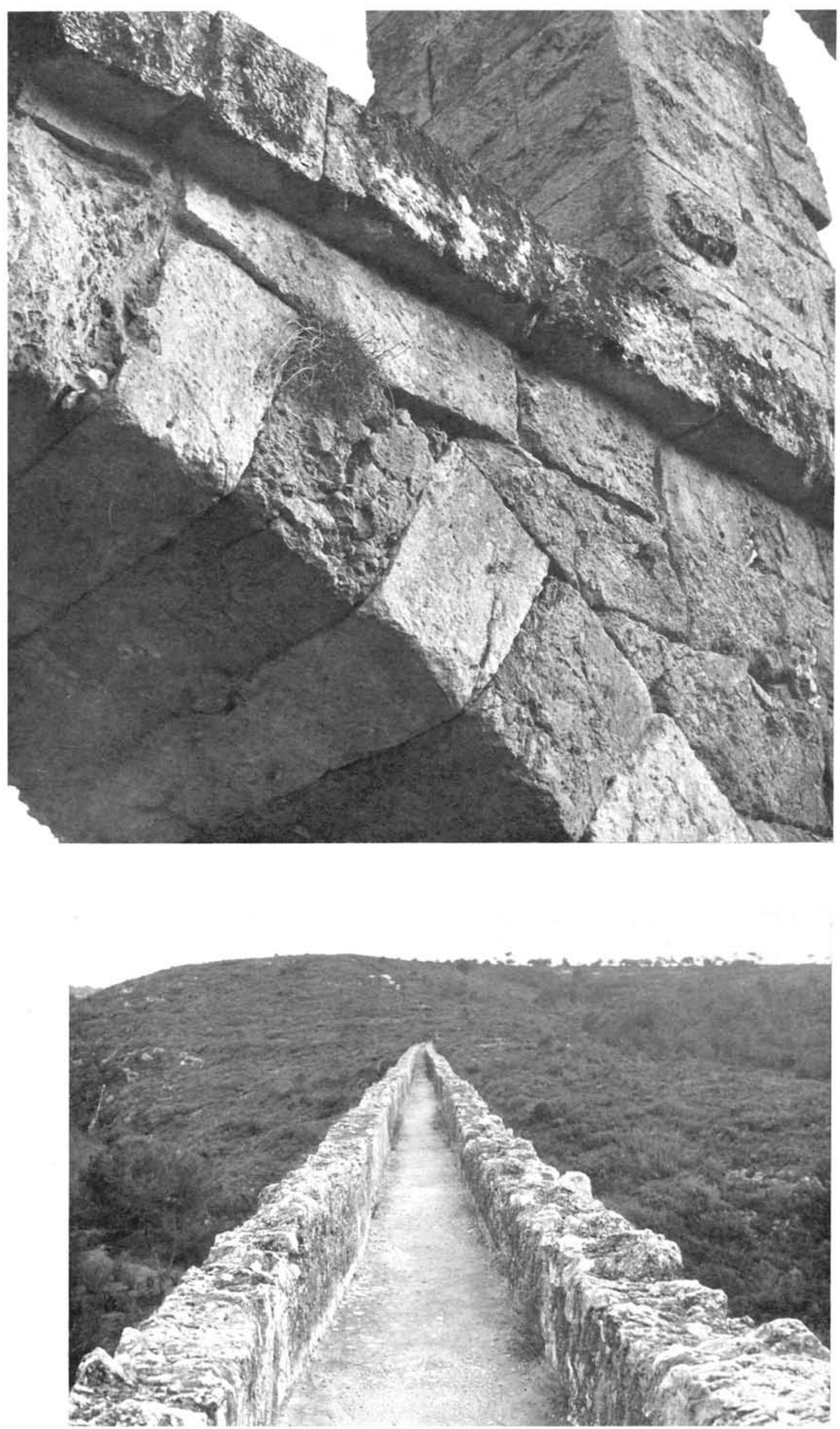

Arco, tímpano y cornisa de una arcada de piso inferior.
Estado actual de la ca.
ja en la alineación del acueducto. 
Zona central de máxima altura:

Zona central de máxima altura: escorzo.

Los arcos del Pont du Gard llegan a $24,50 \mathrm{~m}$ de luz, que es de las máximas en puentes romanos, y además la solución resulta más complicada, pues se superponen tres pisos, dos de arcos de la misma luz, y el tercero con luz terciada. Es lógico que Agripa, a cuyo cargo estuvieron las dos obras, y era intendente de aguas de Augusto, ensayara esta importante innovación en una obra sencilla, y no en una de las de máxima envergadura de la ingeniería romana.

Las cornisas del acueducto de Tarragona son las más simples que pueden idearse, simple resalto de una hilada de sillares, mientras que en Pont du Gard se introducen listeles, cuartos de círculo y cavetos.

Reduciendo a cifras las suposiciones, a partir de las fidedignas del 26-25, estancia de Augusto en Tarragona; la de 33 a. de J. C., ejecución del Aqua Julia; la del 19, correspondiente al Aqua Virgo; y la del 16, fecha de la muerte de Agripa; podemos situar nuestro acueducto al final de los años 20 , que va bien, además, con la fecha del 18 que se atribuye, no sabemos con qué fundamento, al Pont du Gard.

A propósito del Pont du Gard, es preciso deshacer un malentendido que parece derivarse de las referencias que a él se hacen en publicaciones modernas. Esta obra fue construida por los romanos exclusiva-
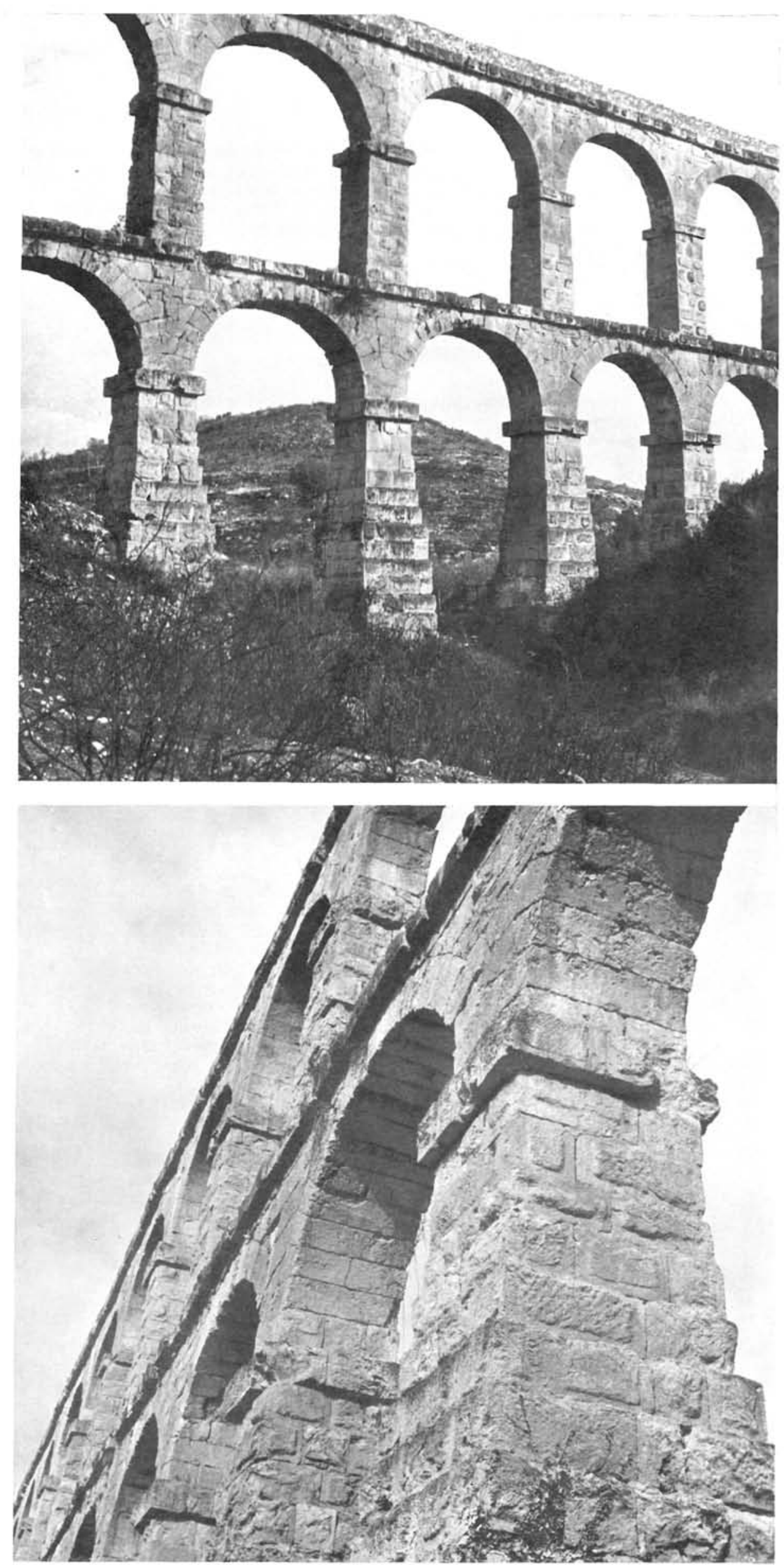
mente como acueducto, quedando un margen de anchura entre la plataforma del primer piso y los pilares del segundo, que podía servir para el paso de caminantes. En el siglo XVII se adosó un puente construido integramente por los ingenieros franceses para la carretera correspondiente. Se adosaron sus pilares a los romanos y se amoldó el tablero al primer piso del acueducto, aunque con un ligero decalaje, puesto que el paso romano es horizontal, y la plataforma moderna tiene rasantes simétricas a dos vertientes.

\section{problemas ingenieriles}

Con arreglo a nuestras hipotéticas deducciones, en este acueducto se aplica por primera vez la solución de la superposición de arcadas para elevar una plataforma, sobre el suelo, a una altura que se considera superior a la que permiten los elementos estructurales disponibles directamente, o a lo que aconseja la utilización económica de la fábrica que va a emplearse. Esta idea de la superposición habría de ser muy fecunda, especialmente en la arquitectura de nuestro país.

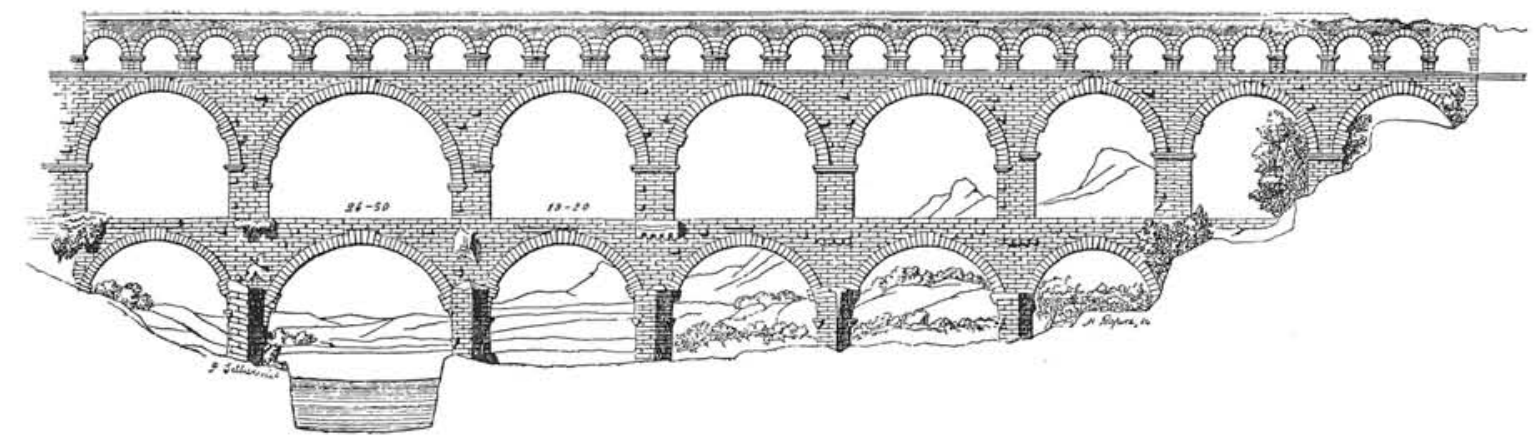

Es el segundo paso en el desarrollo de soluciones del acueducto propiamente dicho. La primera es la de repetición de arcadas con altura variable, de la cual, la primera aplicación extraordinaria está en la zona terminal del Aqua Marcia, que se desarrolla en más de $9,5 \mathrm{~km}$ de longitud. La segunda se debió llevar a cabo indiscutiblemente lejos de la capital, porque el caso más próximo al nuestro, el Pont du Gard, es también anterior al de los arcos neronianos o celimontanos, que son del imperio de Nerón, como ya hemos establecido. Es lógico que estas innovaciones constructivas se introdujeran por los ingenieros hidráulicos, fuera de la capital, pues en esta primera época debieron ser los mismos que dirigían las construcciones de Roma, ya que la trascendencia de un fracaso se atenuaba con la distancia.

La aparición del acueducto como tipo específico dentro de los puentes tiene lugar, como ya hemos dicho, en el terminal del Aqua Marcia. En los pasos de vías o arroyos de la misma conducción, estamos dentro del tipo clásico de puente; pero en la zona terminal que indicamos, el terreno nos ha abandonado, el plano cuasi-horizontal que va definiendo el nivel del agua se ha quedado en el aire, despegándose definitivamente del terreno bajo él, cuando todavía está lejana la meta adonde nos dirigimos. No se puede descender rompiendo presión, artificio conocido de sobra por los ingenieros romanos, puesto que hay que llegar con el agua a abastecer la población de las colinas. Problema nuevo que habían planteado la geografía de la campiña romana descendente desde todos lados hacia la ciudad y el emplazamiento de ésta sobre las siete colinas. Las conducciones anteriores desde fuentes a nivel inferior abastecían únicamente las zonas bajas de la ciudad.

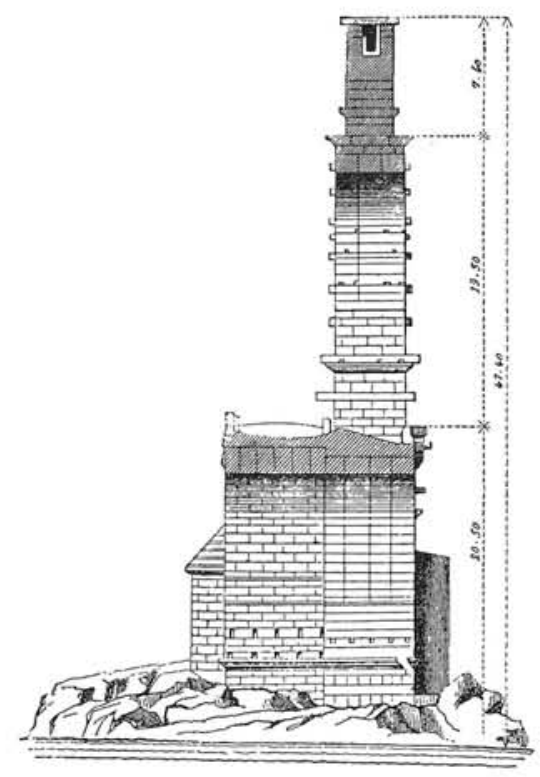

Alzado y sección del Pont du Gard según Darem. berg y Seglio. Se aprecia en la sección el adosado del puente del siglo X VIII (120). 


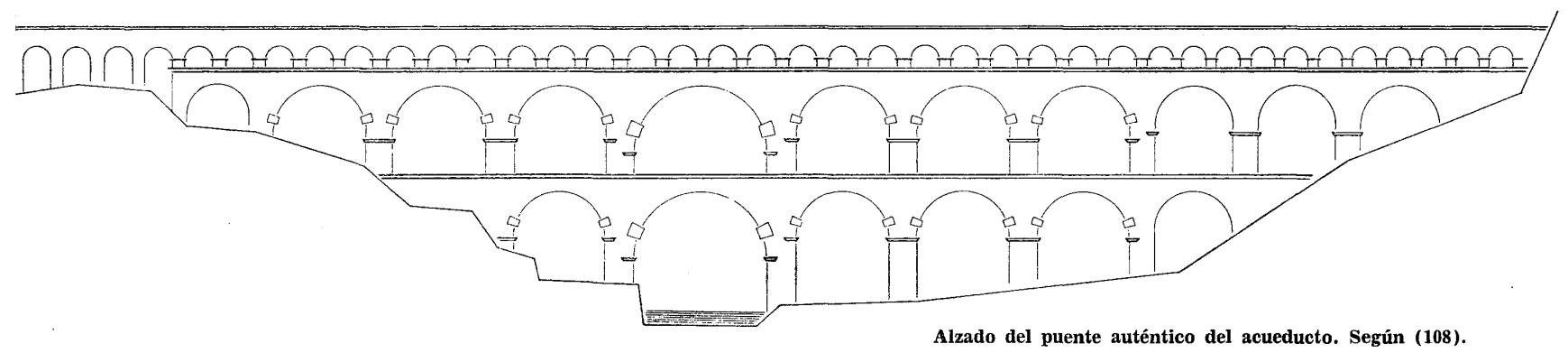

Resolver el problema de mantener en alto la caja del canal en un recorrido de miles de pasos fue una verdadera innovación, y el solo hecho de afrontarlo revela la voluntad de dominio que animaba a ingenieros y gobernantes romanos. Había que levantar más de mil arcadas y es preciso darse cuenta del gran esfuerzo mental y material que se precisa para concebir primero y realizar después, tal ringlera de pilares perfectamente alineados e igualmente repartidos. Es un empeño sólo equiparable al que realizaron los hombres del paleolítico en Karnak.

Desde el punto de vista ingenieril, el acueducto fue la primera versión del viaducto, puente que se desentiende del río, al que desdeña desde la elevación de su rasante.

Como hemos visto ya en las conducciones de la ciudad de Roma, existen dos subtipos de acueductos: el terminal y el acueducto intermedio, en que se salva bien un río o bien una depresión del terreno. En realidad, son sólo dos: el acueducto-puente y el acueducto-viaducto, perteneciendo al segundo, tanto los terminales como los intermedios en que la rasante se despega francamente del terreno.

El tipo viaducto no se da en los puentes romanos, ya que la flexibilidad de la calzada para adaptarse al terreno prepara con antelación la cota de paso del río, bajando y subiendo para reintegrarse en ambos sentidos a la vía correspondiente. El viaducto no ha extendido su campo de aplicación fuera de los acueductos, sino a la llegada de las vías férreas y después con las autopistas, y precisamente por la cualidad análoga de ambas, de su inadaptabilidad al terreno en las zonas accidentadas a consecuencia de la limitación forzosa en la disminución de las curvas, y en la inclinación de sus rasantes. En esta última, el acueducto extrema la exigencia al ser casi horizontal su rasante teórica, por lo cual la adaptación al terreno le obliga a los contorneos sinuosos de la curva de nivel, que en muchos casos pueden atajarse al cruzar por el aire entre dos laderas opuestas.

Este es el caso del acueducto que ahora nos ocupa, salto entre dos laderas que ahorra el contorneo del valle, pero no obligado, como ocurre en los acueductos finales de Roma, Segovia, Toledo, etc. donde la ciudad está erigida en alto y no hay otro recurso para llegar a ella. Ahora tenemos alternativa y es un problema económico el que lo plantea, economía que no es sólo de coste, sino de longitud, muy interesante en explotación, lo que aconsejó cortes en las conducciones de Roma mediante acueductos elevados, introducidos por emperadores reformistas. En estos casos la altura está en relación con el rodeo que corta, siendo un índice de su eficacia, lo que llevó a aumentarla sucesivamente, llegando a pedir la doble arcada por esbeltez excesiva de pilares.

Según nuestras suposiciones, en el acueducto de Tarraco se resolvió por vez primera este problema de la superposición de arcadas, es decir, la de un acueducto sobre un puente, con lo cual se salva la dificultad en dos etapas, enrasando primero un piso intermedio para llegar en el segundo a la altura debida, o repetir una vez más la operación cuando ésta lo aconseje, como es el caso en el Pont du Gard.

En nuestro acueducto esta idea se ha plasmado de un modo definitivo, el primer piso se ha obtenido enrasando los tímpanos de la fila inferior de arcadas y recalcando el nivel con una hilada complementaria de extremo a extremo, que avanza por ambos costados en voladizo, formando de este modo una sencilla cornisa. Sobre ella se repite la misma ordenación, ahora completamente regularizada y volvemos a coronar con idéntica cornisa, sobre la cual se asienta la caja que es la coronación definitiva.

Un defecto de esta disposición, que resalta con más fuerza en este acueducto y en el de Segovia, en los que no existe aglomerante que dé monolitismo a los tímpanos, es el de apoyar los pilares superiores sobre el enjutado de los tímpanos, que rellenando los triángulos curvilíneos entre bóvedas parecen ejercer un efecto-cuña contra ellas. Acentúa la impresión de castillo de naipes que da la superposición de arcadas, lo cual les llevó a reforzar de un modo excesivo los pilares centrales en su zona inferior. Esta disposición la tenemos en unos cuantos acueductos de un solo piso: Chelva, en España; Constantina, en Argelia; etc. 
La evolución morfológica de la idea de superposición empujada por esta insatisfacción del aspecto que da su traducción más sencilla, acentuando las horizontales, condujo, en la serie de acueductos españoles, a la acentuación de las verticales, organizándose los pilares como tema principal, relegando los arcos a un enlace entre ellos a diversas alturas. El ejemplar más perfecto de la serie es el acueducto de los Milagros, de Mérida, ordenado en tres pisos.

Daremos los tres dibujos y fotografía del acueducto denominado Pont du Gard sobre el río de este nombre en la conducción de Nimes, para que puedan compararse su estructura y sus fábricas con las de nustro acueducto. Pueden apreciarse las semejanzas en la estereotomía y en el terminado de los sillares. Probablemente fueron los mismos ingenieros, los constructores de ambos, y parece lógico suponer posterior al Pont du Gard, obra de mucha mayor envergadura y mejor resuelta.

\section{problemas estéticos}

La superposición de arcadas en un acueducto de tipo viaducto, como es el que ahora estudiamos, nos recorta en el segundo piso una faja de cielo, en la cual puede diseñarse con toda libertad el festoneado de la arcada múltiple superior, ya que, ni desde la zona inferior las cimentaciones mandan, ni en las zonas laterales los triángulos de enlace al terreno, tienen importancia frente a la longitud de la banda rectangular donde ha de inscribirse el ritmo monótono de arcos y pilares superiores.

Son 25 arcadas en total, de las cuales las cuatro extremas de un lado pierden por completo sus pilares y sólo 11 reposan sobre la plataforma artificial que les proporciona el piso intermedio, aunque si éste hubiera sido prolongado hasta el terreno por ambos lados pudiera haber recogido casi dos arcadas más por cada lado. Este piso queda cortado bruscamente, mientras que la cornisa superior se prolonga hasta morir materialmente en el terreno.

En este ejemplar se adoptan proporciones que habrán de conservarse por lo menos en los otros acueductos españoles de doble arcada superpuesta. Así, en los huecos superiores se combina un cuadrado con un semicírculo, es decir, altura = vez y media la luz, y se da a los pilares la tercera parte del ancho del vano, proporción esta última que se afinará en Segovia, donde es la cuarta parte. El ático que corona el monumento y que responde escuetamente a la altura de caja es la cuarta parte de la luz. Esta resulta 30 pies, aunque la real se aproxima más a 5,90, en las que hemos medido directamente.

En el piso inferior los arcos se conservan iguales, no así en Segovia, donde son de menos diámetro, pero sí en los dos pisos de Mérida, y los pilares de altura muy variable se van engrosando de modo discontinuo por aumento de sus dos dimensiones. Esta idea se realiza en casi todos los acueductos, exceptuando los Milagros, donde los pilares se mantienen con sección constante en la altura; pero en el caso de Tarragona, la realización ha sido bastante tosca, por la brusquedad de los incrementos sucesivos de sección que les quitan esbeltez.

Con respecto a un puente tenemos esa libertad expresiva que hemos indicado para el piso superior. Se trata de un problema puramente geométrico, sin condicionado por parte del caudal o de la cimentación del cauce; no hay luces desiguales y dentro del perfil triangular o rectangular de cualquier valle rectificamos su geometría, dejando por debajo del piso intermedio la zona de alturas diferentes. Además, el ático que corona toda la obra resulta más estabilizador que el pretil del puente, ya que sus proporciones responden directamente a las de la caja cuando ésta tiene suficiente importancia, o se le da la altura conveniente cuando, como ocurre en Segovia, ésta tiene dimensiones muy reducidas. Además, esta coronación es precisamente el objetivo de la obra que aparece así exaltada en su solemne elevación con una adecuación perfecta de jerarquías en orden ascendente, pues aparece la caja en alto dando la continuidad de su horizontal que serena, y a la par estabiliza, el primer piso de arcadas en su perfección geométrica de ritmo liberado, y el segundo piso en un tercer nivel donde los arcos se aparean con los superiores, los pilares se desigualan, reproduciendo la variación de altura, y se engruesan de modo diferente según el valor de ésta, acentuando su función portante por el aumento de corporeidad en escalones bruscos.

Como ya hemos indicado anteriormente, para los romanos, que buscaban en la monumentalidad de sus construcciones un cauce eficaz a su obstinada voluntad de imposición de poder, fue el acueducto uno de sus logros más perfectos. Se imponen al espectador en sus tres dimensiones: altura fuera de la escala humana, longitud que unas veces es verdaderamente colosal en alineaciones de kilómetros y siempre se alarga por la vibración rítmica de sus arcadas, y espesor que da una esbeltez de verdadero alarde, como ocurre en Segovia. Son elementos característicos en el paisaje donde están incrustados con una referencia remota a su fontanal origen en las llanuras secas y otra muy directa a su utilitario destino. Incluyen en sus dimensiones físicas una cuarta dimensión la tempórea, hecha distancia al origen, por el fluir del agua y a su iniciación por el nombre del emperador, constituyendo un monumental reloj de agua, dando en quinarios de agua utilizable el transcurso del tiempo, que se transfundía a la vital necesidad de los ciudadanos, contribuyendo a su romanización. 


\section{referencias históricas y literarias}

\section{acueductos romanos en general}

(100) S. J. FRONTINUS: DE AQUAE DUGTU URBIS ROMAE. Hemos utilizado la edición de la Collection des Universités de France, publicada por Les Belles Letres, bajo la dirección de la Association Gillaume Budé. París, 1944.

(101) PARKER: ARCHAEOLOGY OF ROME, vol. VIII the Aqueducts Oxford, 1876.

(102) E. B. VAN DEMAN: THE BUILDING OF THE ROMAN AQUEDUCTS. Carnegie Institute of Washington, 1934. Hemos utilizado los fotograbados de esta obra referentes al Aqua Claudia y Aqua Alexandriana.

(103) TH. ASHBY: THE AQUEDUCTS OF ANCIENT ROME. Edición de I. A. Richmond, en Clarendon Press. Oxford, 1935.

(104) G. LUGLI: MONUMENTI ANTICHI DI ROMA E SUBURBIO. II LE GRANDE OPERE PUBLIGHE. Roma, 1934, cap. V, Gli Acquedotti, p. 329-402.

\section{acueducto de Tarragona}

(110) E. FLOREZ: ESPAÑA SAGRADA. Tomo XXIV, pág. 230-1.

16. Una de las obras más notables que labró Tarragona fue el que llamaban Puente de las Ferreras, y es un magnífico Aqüeducto para conducir agua á la ciudad: pues siendo populosa, como capital de la Provincia, y esmero de la grandeza de los Romanos, necesitaba mucho surtido de agua: $y$ en efecto perseveraron muestras de conductos por varias partes, como reconoció Pons de Icart, y expuso en el cap. 34. Con el tiempo se han ido destruyendo los vestigios: pues uno que reconoció Pujades en el año 1596 faltaba á los tres años después, como afirma en el fol. 74 .

17. El que ha resistido á los siglos, y mereció ser respetado de todas las Naciones enemigas, es el mencionado Puente de las Ferreras, á una legua de la ciudad, por la parte del Norte, que empezaba á tomar agua á quatro leguas de Tarragona, junto al Real Monasterio Cisterciense de Santas Creus, y cerca del Río Gayá, donde estaba la torre, ó Arca principal, en que dicen vivía el Prefecto de las aguas. Desde allí bajaba el aqüeducto á Villarodona, y Vallmoll, tirando ácia la Ciudad. Una legua antes de Tarragona puso la naturaleza unos collados, que por la hondura intermedia no permitían la dirección de la agua: pero el arte y la grandeza de ánimo venció el estorvo, erigiendo de collado á collado un Puente, por donde el agua corriese.

18. Pujades, en el fol. 74, puso tres órdenes de arcos unos sobre otros. Pero no sé qué fundamento halló para los tres: pues Icart no vió más que dos, y éstos
(105) G IUGLI LA TECNICA EDILIZIA ROMANA, 2 vol. Bardi editore. Roma, 1957. Hemos tomado los fotograbados de algunos acueductos de la ciudad de Roma. Aqua Alexandriana.

(106) M. E. BLAKE: ANCIENT ROMAN CONSTRUCTION IN ITALY FROM THE PREHISTORIC PERIOD THROUGH THE FLAVIANS. Carnegie Institution Washington, 1947-59.

(107) E, NASA: BILD LEXIKON ZUR TOPOGRAPHIE DES ANTIKEN ROM, 2 tomos: Deutsches Archäologisches Institut Tübingen, 1962. Hemos to mado los fotograbados correspondientes al Aqua Virgo, Aqua Marcia y Tépula.

(108) G. PICARD: L'EMPIRE ROMAIN. Office du Livre. Friburgo, 1965.

(109) COSIO-PIJOAN: SUMA ARTIS. Historia general del arte. Tomo V. Arte romano. Hemos tomado los fotograbados correspondientes a acueductos en provincias africanas.

persisten hoy, sin rastro de otra cosa. El orden inferior es de once arcos: el de encima, por donde corría la agua, tiene veinte y cinco. Los once del medio son iguales, porque estrivan sobre la línea en que rematan los once de abajo: todos los demás, así inferiores como superiores, son desiguales en lo alto, porque se van acomodando al suelo, que desde lo más bajo entre los dos collados va subiendo poco á poco hasta las cimas, y cerca de lo más alto, debe el arco ser más pequeño Los más altos son los inferiores del medio, que estrivan en lo más profundo del suelo. La altura total es de treinta y dos varas y međia, según la midió Icart: las veinte y media corresponden á los arcos inferiores: las demás á los de encima. Lo largo es doscientas y treinta y cinco varas en el canal del agua: lo ancho dos varas y media.

19. El modo más fácil para enterarse de todo es ver el alzado de la fábrica, según la delineó $\mathrm{D}$. Antonio Alcedo, Teniente en las Guardias Españolas, que se sirvió comunicármela, y es como muestra la Estampa, que damos á la vista (ver dibujo [1]).

(111) ANTONIO PONZ: VIAJE DE ESPANA. Madrid,

A propósito de la restauración integral de la conducción, existen las siguientes citas:

Tomo X. Prólogo: "No créa Va. que séa esta una de las obras de mayor monta entre las que este benigní simo Prelado tiene proyectadas, para beneficio de esta 
Ciudad; porque yo conceptúo mayor sin comparación, la de restituir a su costa el famoso antiguo aquieducto, tal vez el de mayor extensión que hicieron los Romanos fuera de Italia, para conducir las aguas desde el lugar llamado "Pont de Armentera" a esta Ciudad, que la incuria, o los cuatrocientos años de esclavitud con la invasión morisca, que sufrió esta tierra, desde 713 hasta 1.117 , tenía absolutamente inutilizado.»

"A este importante objeto y santo fin, mandó el Señor Arzobispo (J. de Santiyán y Valdivielso) levantar un plan geométrico del mencionado aquieducto, y sacado el plan, dispuso S. I. la abertura del antiguo conducto, a que se dió principio el 17 de Abril del presente año continuándose sin intermisión por los más hábiles mi nadores de este país; habiéndose ya hecho patente, que desde esta ciudad hasta el mencionado Lugar de "Pont de Armenteran, tiene de largo cincuenta y cinco mil, setecientas sesenta y tres varas, o pasos catalanes; y de su estado actual resulta que de aquieducto arruinado se hallan diez $\mathrm{y}$ nueve mil quinientas $\mathrm{y}$ veinte $\mathrm{y}$ ocho varas: de obra reparable, veinte mil ochocientas y ochenta y dos; y de mina subterránea quince mil trescientas cincuenta y tres; quedando esta abierta ya a satisfacción del Prelado, y de cuantos la reconocen, admirán dose todos de la solidez, primero, y estado de obra tan antigua; expuesta a la voracidad de los siglos, a la barbaridad, y a la ignorancia. De la sola empresa de esta obra entenderá V. el magnífico espíritu de este Señor Arzobispo, que hará cosas grandes y magníficas, si Dios nuestro Señor le alarga la vida..."

(Copia de un trozo de la carta del Arzobispo al Marqués de Floridablanca, que es el siguiente): «Gozoso con haber salido bien de esta empresa, y mucho más con el socorro que hallaron en ella tantas familias, tengo premeditada, para que les continúe el alivio, otra obra de las más vastas y necesarias a este terreno de cuantas se pueden pensar en el día, que es la reedificación a mis expensas del famoso aquieducto de los Romanos para introducir el agua en esta su antigua Metrópoli ( $\tan$ escasa de ella al presente, que no tiene fuente alguna), cuya delineación y longitud prodigiosa reconocerá $\mathrm{V}$. E. por el plan que, custodiado en un cañón de hoja de lata, me tomo la libertad de remitirle hoy, por el correo con sobreescrito separado: pero como prevéo, que una obra de esta naturaleza no dexará de padecer, como sucede a otras de menor clase, algunas contradicciones de los que viendo sin destino aquellas aguas después de tantos siglos, se las aplicaron para regadío de sus tierras, o se las esta blecieron por la Intendencia de este Principado para que se aprovechasen del usufructo (indemne siempre la propiedad, como aquí se acostumbra): suplico rendidamente a V. $\mathrm{E}$. que en el caso que merezca su aprobación dicho diseño, se digne facilitarme de nuestro Augusto Monarca el permiso, facultades, y auxilios conducentes, para que nadie me perturbe en un pensamiento de que resultarían forzosamente imponderables ventajas, así al ramo de Agricultura, por las muchísimas posesiones que se podrían regar al paso, como al de distintas fábricas, o cualquiera otra especie de industria, inseparable de todo buen gobierno y civilidad: sobre todo sería grande a todas luces el beneficio que seguiría a estos habitantes, que se ven con frecuencia en la dura precisión de beber agua corrompida de las cisternas, a poca sequedad que sobrevenga, y de este modo, no solo quedarían plenamente socorridos, sino que lograría esta memorable Ciudad (que no es sombra de lo que fué), volver en parte a su antiguo lustre y esplendor, consiguiéndose igualmente para mayor gloria de nuestra Nación, que salga de entre el olvido y obscuridad de los tiempos, una fábrica de las más útiles y suntuósas, que emprendieron los Romanos, que aún en el día es la admiración de cuantos la ven, desde que por mi dirección se empezó a descubrir y limpiar parte de ella.»
(Continúa refiriéndose al acueducto en Tomo $\mathbf{X}$, Carta VI, núms. $67,68,69$ y 71.$)$

67. He ido en su compañía a reconocer una de las antigüedades más importantes de esta ciudad, cuya existencia, si se verificase, sería preferible a cuantas hoy permanecen en ella. Es el antiguo acueducto romano, que caminaba hasta Tarragona desde Pont de Armentera, junto a un monasterio de Cistercienses llamado Santas Cruces, cerca del río Gayá, donde tenía su origen, siendo su curso de seis o siete leguas. El Hospitalet, que es un paraje a donde llegamos, distante cuatro leguas de Tarragona, suministraba caudal abundante a dicho acueducto, además del que traía hasta allí, cuya dirección se reconoce en diferentes sitios, a veces superficial, a veces profundizado en la tierra y en parajes atravesando largas distancias de peña viva trasforada.

68. Las aguas del Hospitalet, que parte nacen en la Encomienda de la Orden de San Juan, y parte junto al caserío que llaman de Torrellés, se introducen ahora en un barranco, y por el término de Vallmoll van a parar al río Francolí, llamado antiguamente Tulcis. Este viaje lo hemos hecho, no solamente por satisfacer nuestra curiosidad, sino también los deseos del ilustrísimo señor arzobispo don Joaquín de Santiyán y Valdivielso, quien sepa usted que se ha propuesto la restauración total de esta obra importantísima para Tarragona, y la empresa tiene ya su principio con tan buenos auspicios, como que habiendo representado dicho prelado a su majestad para que protegiese esta obra, que a sus expensas quiere efectuar, ha tenido las contestaciones más favorables que a nombre de su majestad le ha enviado el excelentísimo señor conde de Floridablanca en 10 de Marzo de 1.782.

69. Según el fervor y constancia del señor arzobispo, no dudo que perfeccionará su ardua y costosa empresa, en cuyo caso será, sin duda, en esta parte un verdadero restaurador de la gran Tarragona, reducida hoy a un esqueleto de lo que fué, habiendo carecido de las aguas, que antiguamente entraban abundantemente en dicha ciudad por este y otros acueductos que tenía. Desde luego, podrán contar sus vecinos con el beneficio de beber agua buena y salir de la penuria en que ahora se hallan, bebiéndola de algibes, $\mathrm{y}$ a veces corrompida, pues aunque tienen un profundísimo pozo en la ciudad, donde la hay manantial, es casi nada la que sube por medio de una máquina, y poco agradable; tenđrán los vecinos proporción y facilidad para establecer fábricas, para regar terrenos y otros mil beneficios. El señor arzobispo habrá hecho una limosna universal y permanente, benéfica a los presentes y venideros, y será el único entre tantos y tan grandes prelados como ha tenido esta iglesia, que haya tenido y perfeccionado uno de los mayores bienes que son imaginables.

(El día 5 de Julio de 1.783, después que se escribieron la primera vez estas cartas, falleció, con gran sentimiento de Tarragona y de todo el arzobispado, este benéfico prelado; y aunque dejó caudales para continuar la restauración del acueducto, acaso no bastarán para su conclusión total; lo que no hubiera sucedido si su vida hubiese sido más larga; pero es muy de creer que, hallándose la obra muy adelantada, no falten por un camino $u$ otro, medios de concluirla.)

71. El puente que llaman de las Ferreras es un soberbio residuo del antiguo acueducto de que he hablado. Consiste en una fábrica de dobles arcos para salvar una hondura entre dos colinas y llevar nivelada el agua. A proporción que se eleva el terreno, se disminuye la elevación de los arcos; los inferiores, como que ocupan paraje más estrecho, son once, y los de encima, vein- 
ticinco; son de piedras sillares. La altura de esta magnífica obra es de treinta y dos varas y media; lo largo de doscientas treinta y cinco, y lo ancho, dos y media.

(112) BARON DE BURGOING: UN PASEO POR ESPANA. 1777-95. Edición J. García Mercadal, p. 1062.

los vestigios de un acueducto de seis a siete leguas de recorrido, de cuya restauración se habló en 1.782

\section{(113) J. TOWSEND: VIAJE A ESPAÑA HECHO EN LOS} ANOS 1786-7. Edición J. García Mercadal.

El acueducto lleva el agua a la ciudad desde siete leguas de distancia y atraviesa un profundo barranco sobre un puente que tiene 700 pies de largo y más de 100 de alto. Tiene por abajo 11 arcos y arriba 25. Ha sido reparado a costa del último arzobispo.

(114) SOMORROSTRO: EL ACUEDUCTO DE SEGOVIA, 1820. Descripción del acueducto de Tarragona en página 13.

(115) CEA BERMUDEZ: SUMARIO DE LAS ANTIGÜEDADES ROMANAS QUE HAY EN ESPANA GÜEDADES ROMAN
Madrid, 1832, pág. 7.

El agua iba a esta capital desde cerca del monasterio Cisterciense de Santas Creus, distante de ella cuatro leguas. El Puente de las Ferreras está situado a una legua de Tarragona hacia el norte, entre dos collados, y consta de dos órdenes de arcos, unos sobre otros. Lo largo de todo el trozo es de 235 varas y lo alto por el medio de $32 \frac{1}{2}$, de las cuales $20 \frac{1}{2}$ pertenecen a los arcos inferiores y 12 a los superiores, que tienen de espesor $2 \frac{1}{2}$

Cerca del Circo máximo descollaba un suntuoso edificio, tenía 425 varas de largo y 225 de ancho. Se encuentran entre sus ruinas bóvedas de piedras muy grandes... Rodeaba este gran edificio un acueducto, y otro pasaba por delante de la puerta principal.

\section{(116) MADOZ: DICGIONARIO GEOGRAFICO (1849)}

Tomo XIV, pág. 650.

\section{TARRAGONA.-Acueducto.}

Llámase en Tarragona Puente de las Ferreras, el res petable monumento a que nos referimos, que tomaba las aguas del río Gayá, 1,5 leguas al E. de la ciudad cerca de Altafulla, conduciéndola hacia la parte de la Secuita y por la casa de campo llamada la Tallada, en la que residía el prefecto de las aguas: desde el punto de su origen seguía por suntuósas galerías y conductos subterráneos hasta el citado puente, el cual se eleva en una hondonada a una hora escasa al N. de Tarragona, junto a la carretera de Valls, nivelando y uniendo aquel espacio dos líneas de arcos unos encima de otros: los 25 superiores conducían el agua de una parte a otra de las montañas, sostenidos por otros 11 que forman el cuerpo inferior, todos iguales en dimensiones, pero en virtud de la vertiente de las montañas, los pilares de los arcos laterales van disminuyendo gradualmente hasta quedar en sus extremos algunos arcos sin ellos. Su total elevación desde la parte más honda del terreno es de $83 \frac{1}{2}$ pies; los pilares inferiores tienen de ancho en su base 12 pies, y rematan en espira de seis pies de frente, encima de la cual corren las impostas de segundo orden: luz del arco de pilar $22 \frac{1 / 2}{\text { pies; }}$ longitud total de la obra 876 , y longitud de la parte ar- queada tomándola en el firme del pilar en ambos extre mos 725; su forma es bella y sencilla, a la par que gra ciosa e imponente, construída con grandes sillares almohadillados, y a excepción de 3 ó 4 que faltan en su parte superior central, el todo se halla perfectamente conservado, estando unidas y afianzadas las piedras por su mismo peso, sin ninguna clase de betún: el vulgo, a imitación de lo que sucede en Segovia, le llama Puente del Diablo. Desde esta fábrica queda borrado enteramente el conducto, el cual aparece a mucha distancia en el camino del Angel, cerca de la ciudad en un largo trozo de galería abovedada, y cortado en aquel sitio desaparece del todo. Según la dirección y declive del terreno, el agua penetraría en la ciudad por las inmediaciones de la puerta del Rosario para distribuirse en varias direcciones, desprendiéndose del conducto principal otra hijuela que partía en línea recta por el exterior de la ciudad, cuyos vestigios se manifiestan en el foso junto a la puerta de San Francisco y parte superior a la izquierda del mismo, yendo a parar al puerto; y quizá sería continuación de la misma un trozo de galería subterránea que existe en el glásis del fuerte real; y es de creer que continuáse al baño público que hemos dicho antes, porque en aquel mismo sitio se descubrió la entrada de una galería subterránea, fabricada con grandes sillares de una vara de ancho y $1 \frac{1 / 2}{d e}$ elevación

Debemos hacer mérito en este lugar de otra obra hidráulica, cuyos autores y objeto son desconocidos. En la plaza de la Fuente y a una vara de distancia de la misma al O., hay una losa que cierra la entrada de un profundo pozo, practicado en la dura peña; en sus costados una especie de estancias cuadradas, alternadas entre sí en forma de pisos, siendo necesario valerse de una escalera de mano para bajar de uno a otro hasta el undécimo; y en su mayor profundidad aparece una gran hendidura perpendicular, que contiene un caudal inmenso de agua. Ignorada sin duda esta obra desde largos años, fue descubierta en el siglo XV y habiendo hallado su agua de la mejor calidad, el arz. D. Domingo Ramos mandó colocar un ingenio, el cual surtió por muchos años a los vecinos hasta que se condujeron las aguas exteriores y fue obstruída la entrada de este gran depósito.

(117) TARRAGONA MONUMENTAL, de J. F. ALBIÑANA y A. BOFARULL.-Tarragona, 1849, páginas 166-9.

Según los monumentos y restos existentes durante el dominio de los romanos, Tarragona estuvo abundantemente surtida de aguas que fueron a tomar del río Gayá, una legua y media distante de esta ciudad, cerca de Altafulla, conduciéndola hacia la parte de la Secuita y por la casa de campo llamada la Tallada, en la que residía el prefecto de las aguas, siguiendo desde aquel punto por galerías y conductos subterráneos hasta el famoso puente llamado de las Ferreras, monumento respetable perfectamente conservado, lámina 24 , el cual se eleva en una hondonada a una hora escasa por la parte del norte de Tarragona, junto a la carretera de Valls; nivelando y uniendo aquel espacio dos líneas de arcos unos encima de otros.

Los veinte y cinco superiores conducían el agua de una parte a otra de las montañas, sostenidos por otros once que forman el cuerpo inferior, todos iguales en dimensiones.

Como las vertientes de las montañas son diagonales, y en ellas apoya toda la fábrica, por la misma razón los pilares de los arcos laterales van disminuyendo gradualmente hasta quedar en sus extremos algunos arcos sin ellos. 
Han venido más de una vez a nuestras manos dibujos y grabados del Puente de las Ferreras. Unos representan a este monumento con tres órdenes de arcos, otros con más arcos de los que en sí contiene, y no pocos con los pilares iguales. El motivo de estas contradicciones no es, a nuestro ver, el que indicamos de que no es posible representar en el papel lo que no se ha visto ni medido. Los pilares del orden inferior de este acueducto rematan en espira y todo el orden restante podemos darlo por exacto por lo mucho que lo hemos examinado y medido.

Su total elevación desde la parte más honda del terreno es de ochenta y tres pies y medio; ancho de los pilares en su base, doce; debajo de las impostas, seis y medio; luz del arco de pilar a pilar, veinte y dos y medio; longitud total de la obra, ochocientos setenta y seis, y longitud de la parte arqueáda tomándola en el firme del pilar en ambos extremos, setecientos veinte y cinco pies.

$\mathrm{Su}$ forma es bella y sencilla a la par que graciosa e imponente, construída con grandes sillares almohadillados; y a excepción de tres o cuatro que faltan en su parte superior central, el todo se halla perfectamente conservado; destacando ese bello monumento del fondo obscuro del valle, por el tinte anaranjado que los siglos han impreso sobre aquellas piedras unidas y afianzadas con su mismo peso sin ninguna clase de betún.

Después del acueducto queda borrado enteramente el conducto, el cual aparece a mucha distancia en el camino del Angel cerca de la ciudad en un largo trozo de galería abovedada, y cortado en aquel sitio, desaparece del todo.

(118) F. FULGOSIO: CRONICA GENERAL DE ESPA NA. Tomo: Cataluña. 1870 . Se ha utilizado el dibujo $[35]$.

\section{dibujos}

[31] Vista de los arcos y acueducto llamado el Puente de las Ferreras mirando al norte distante una legua de la ciudad de Tarragona, publicado en la «España Sagradaus, del P. Enrique Flórez, tomo XXIV, página 230, dibujado por D. Antonio Alzedo, Teniente de las Guardias Españolas. Escala gráfica en pies castellanos. Grabado de $42 \times 11 \mathrm{~cm}$. Gil sculps.

[32] Vista pintoresca de los acueductos de Tarragona, del "Voyage pittoresque de l'Espagne», de A. de Laborde. Tomo I, pág. 32, pl. LV, tamaño $35,50 \times 23,50$ centímetros. Dessiné par Alexandre de Laborde. Gravé à l'eau forte par Baugean. Terminé par Dequevanvillier. Aparece la anécdota de un caballero cruzándolo que describimos en el texto.

[33] Detalles y cortes de diferentes monumentos antiguos de Tarragona, de la misma obra que el anterior. Tomo I, pág. 32, pl. LVI. Forma la parte infe-
(119) P. PIFFERRER: CATALUNA: SUS MONUMEN. TOS Y ARTES: Se ha utilizado el dibujo [36].

(120) DAREMBERG \& SAGLIO: DICTIONAIRE DES ANTIQUITES. Tomo II, pág. 342 .

El acueducto de Tarragona tiene también un doble orden de arcadas, está construido con sillares almohadillados; su altura total es de $31 \mathrm{~m}$ y su longitud de 218. Los pilares del piso inferior tienen talud por sus cuatro costados; los superiores están enrasados en fachada con la última hilada de los anteriores y disminuyen únicamente en las caras internas de las bóvedas.

(121) PUIG Y CADAFALL: HISTORIA DE LA ARQUITECTURA EN GATALUNA.

PONS DE ICART: LIBRO DE LAS GRANDEZAS DE TARRAGONA. Lérida, 1572 y 1883.

(122) MONUMENTOS NACIONALES. Núm. 874; tomo II, págs. 314-15

Traía las aguas del Gayá por el valle del Francolí con un recorrido total de 25 kilómetros. Su parte monumental visible, Puente de las Ferreras; a unos $4 \mathrm{~km}$ al norte de Tarragona, son las arquerías de piedra, con dos órdenes, con once arcos en la línea inferior y veinticinco en la superior. Su longitud total es de 200 metros, su mayor altura llega a 26 metros. La luz de sus arcos es de-6,40. Se piensa que debe datar de principios del Imperio y es parecido al llamado puente del Gard, que llevaba las aguas a Nimes. Le quita esbeltez lo gruesos que por refuerzo son sus pilares.

(123) A. SCHULTEN: TARRACO. Barcelona, 1948, páginas $55,59, \mathrm{y}$ foto 10

rior de un grabado con detalles del anfiteatro de Tarragona, teniendo su escala gráfica en pies. Longitud del grabado, $44,50 \mathrm{~cm}$.

[34] Acueducto romano, de la obra "Tarragona monumental», de J. F. Albiñana y A. Bofarull. 1849. Lámina 24 , litografía de $15 \times 10 \mathrm{~cm}$. D. b. del natural y lit. por D. Soberano. Lit. Alegret y Cie. REUS.

[35] Acueducto de Tarragona, de la obra "Crónica General de Españan, tomo Cataluña, de F. Fulgosio (1870), pág. 25. Reproducido a su tamaño.

[36] Acueducto llamado de las Ferreras, de la obra "Cataluña: sus monumentos y artes», de $\mathbf{P}$. Pifferrer (1884), pág. 485. Fotograbado reproducido a su tamaño. 